\title{
Vertical turbulent nitrate flux from direct measurements in the western subarctic and subtropical gyres of the North Pacific
}

\author{
Hitoshi Kaneko ${ }^{1} \mathbb{0} \cdot$ Ichiro Yasuda $^{2} \cdot$ Sachihiko Itoh $^{2} \cdot$ Shin-ichi Ito ${ }^{2}$
}

Received: 15 June 2020 / Revised: 25 September 2020 / Accepted: 28 October 2020 / Published online: 6 January 2021

(c) The Author(s) 2021

\begin{abstract}
Vertical turbulent nitrate fluxes were estimated in the western North Pacific from direct measurements of vertical turbulent mixing and vertically continuous nitrate profiles during the summer of 2008. We made three north-south transects that covered the area from the subarctic to the subtropics including a section along the Emperor Sea Mounts. Subsurface fluxes generally showed an increasing trend with increasing vertical gradient of nitrate from oligotrophic subtropical to non-oligotrophic subarctic waters. Enhanced fluxes $\left[O\left(10^{-6}\right) \mathrm{mmol} \mathrm{m}^{-2} \mathrm{~s}^{-1}\right.$ ] due to elevated mixing [vertical diffusivity: $O\left(10^{-5}\right) \mathrm{m}^{2} \mathrm{~s}^{-1}$ ] were observed, especially over the Emperor Sea Mounts. It is suggested that the internal tide generated by the topography enhanced the vertical mixing. In other subarctic areas, the fluxes were estimated as $O\left(10^{-7}\right) \mathrm{mmol} \mathrm{m} \mathrm{m}^{-2} \mathrm{~s}^{-1}$. The same order of fluxes was also found in the frontal area between the subarctic and subtropical gyres, the Kuroshio-Oyashio Transition Area. Enhancement of fluxes in the frontal area, including the Kuroshio Extension, was also observed at mid-depth regions, and their vertical divergence suggested nitrate transport from North Pacific Intermediate Water to lighter densities. In the frontal areas, the enhancement of turbulence is caused by the surface wind rather than the internal tide. In contrast, in the subtropical regions, subsurface fluxes were estimated as $O\left(10^{-8}\right) \mathrm{mmol} \mathrm{m}^{-2} \mathrm{~s}^{-1}$ owing to the small nitrate gradient even where diffusivity was enhanced. In these regions, enhancement of diffusivity, including that at mid-depths, corresponded to the elevation of the internal-tide dissipation, in addition to that of surface turbulence.
\end{abstract}

Keywords Western north pacific $\cdot$ Vertical turbulent nitrate flux $\cdot$ Emperor Sea mounts $\cdot$ Kuroshio extension $\cdot$ KuroshioOyashio transition area $\cdot$ Chlorophyll $a$

\section{Introduction}

Turbulent mixing is an essential process for the vertical transport of heat, salt, and substances, including nutrients, in the stratified ocean (e.g., Thorpe 2004). Such vertical

Electronic supplementary material The online version of this article (https://doi.org/10.1007/s10872-020-00576-0) contains supplementary material, which is available to authorized users.

Hitoshi Kaneko

h_kaneko@jamstec.go.jp

1 Mutsu Institute for Oceanography, Japan Agency for MarineEarth Science and Technology, 690 Kitasekine, Sekine, Mutsu, Aomori 035-0022, Japan

2 Atmosphere and Ocean Research Institute, The University of Tokyo, 5-1-5, Kashiwanoha, Kashiwa, Chiba 277-8564, Japan nutrient transport also has an important role in phytoplankton production, taxonomic composition, and size structure in the euphotic layer (Chisholm 1992). Vertical turbulent nitrate flux is a key component of primary production (Eppley et al. 1979; Lewis et al. 1986; Carr et al. 1995). It is one of the main pathways for nutrient supply to the euphotic layer in regions where the surface water is permanently (e.g., subtropical oceans) or seasonally (e.g., subarctic oceans) deficient in nitrate. Nitrogen fixation is another source of nitrogen for new production in regions deficient in surface nitrate (e.g., Mouriño-Carballido et al. 2011; Horii et al. 2018). Evaluation of the vertical turbulent nitrate flux based on direct observations allows us to investigate the surface nitrogen path quantitatively. Moreover, observations of vertical turbulent fluxes into mid-depth regions also provide information on nitrate transport in deeper waters that is also important for understanding biogeochemical cycles. 
Estimates of the vertical turbulent nitrate flux are obtained in practice by multiplying the vertical nitrate gradient by the vertical eddy diffusivity (e.g., Lewis et al. 1986). Although several studies of turbulence with basinscale coverage have advanced knowledge about turbulence in the North Pacific (Moum and Osborn 1986; Nagasawa et al. 2007; Mori et al. 2008; Fernández-Castro et al. 2014; Itoh et al. 2020), concurrent measurements of the nitrate profile and vertical diffusivity are rare except over the western boundary region (e.g., Kaneko et al. 2013; Nagai et al. 2019; Tanaka et al. 2019) and eastern boundary region (Hayward 1987; Fernández-Castro et al. 2015). Therefore, basin-scale variability of vertical nitrate flux in the region has yet to be clarified, especially in the western North Pacific. From the perspective of nutrient circulation, the western North Pacific is important because the region has a distinctive circulation, whereby North Pacific Intermediate Water originating from the Okhotsk Sea (Yasuda 1997) has been identified as affecting nutrient distribution from the surface to mid-depths, which differs from the influence of Subantarctic Mode Water in other oceans (Sarmiento et al. 2004).

In the present study, we focus on the basin-scale variability of vertical nitrate flux in the western North Pacific. The western North Pacific is divided by wind-driven circulation into the subarctic gyre, the subtropical gyre, and the tropical region. The subarctic gyre is characterized by an intense maximum of the vertical gradient of nutrients (i.e., nitracline) and pycnocline below the surface waters (from the surface to dozens of meters in depth) owing to upwelling caused by the surface wind-driven circulation, whereas the subtropical gyre has deeper nitracline and pycnocline caused by downwelling. Thus, it is expected that active vertical nitrate transport into the euphotic zone occurs in the subarctic gyre. In addition to such gyre-scale contrast, the local variability in fluxes may be modified by turbulence in the subsurface pycnocline (including the seasonal thermocline, at depths of dozens to several hundreds of meters) caused by local topographic and atmospheric influences, and the relative vertical position of the nitracline. Subsurface turbulence in the open ocean is generally caused by internal waves generated from internal tides around characteristic topography, including the Emperor Sea Mount Chain (Niwa and Hibiya 2001; Nagasawa et al. 2007), as well as by the surface wind. Thus, the Emperor Sea Mount Chain (ESM) might also have a specific ecological character; if the level of the nitrate flux differs from that in surrounding basin areas.

Another subarea of the western North Pacific between the southern bound of the subarctic gyre and the northern bound of the subtropical gyre is expected to have the characteristics of an ecotone. The bounds are independently recognized as the subarctic front and the Kuroshio Extension (KE), and the area between the bounds is known as the Kuroshio-Oyashio Transition Area (KOTA; Yasuda 2003). The KOTA contains many mesoscale eddies and fronts and has a complex distribution of water masses. Previous observations conducted in the western boundary region have indicated that the nitrate flux is enhanced in the frontal areas (Kaneko et al. 2013; Nagai et al. 2019; Tanaka et al. 2019). Strong currents accompanied by intense fronts can affect the intensity of turbulence by modulating the propagation and breaking of internal waves (e.g., Whalen et al. 2018) and through direct energy supply (e.g., D'Asaro et al. 2011). Thus, turbulence enhancement and subsequent elevated vertical fluxes may occur in regions with complicated frontal structures such as the KOTA. The nature of turbulence is such that enhancement would be expected to occur intermittently and unevenly in the vertical direction rather than continuously and over a large depth range. This generally makes the estimation of the level of turbulence and fluxes difficult; however, fluxes are rarely measured in the oceanic part of the KOTA, so it is worthwhile conducting and accumulating estimates based on field observations.

With respect to nitrate circulation, particularly at middepths, the North Pacific Intermediate Water plays a key role in nutrient transport from the subarctic gyre to the subtropical gyre through the KOTA. In addition to this horizontal transport, the upward flux of nutrients from North Pacific Intermediate Water to lighter densities that is caused mainly by turbulent mixing may be critically important in the subtropical gyre. Sarmiento et al. (2004) suggested that North Pacific Intermediate Water is expected to have an important role in surface biological activity at lower latitudes. However, as latitudinal and vertical coverage of the measurements are still limited to examining the role of vertical mixing of basin-scale nutrients, the location of major turbulent nitrate transport from North Pacific Intermediate Water in the subtropical gyre has been unclear. Such transport could constitute part of the inter-gyre transport of nitrate.

To reveal the basin-scale distribution of the vertical turbulent nitrate flux in the western North Pacific, we made concurrent observations of turbulence and nitrate along three north-south transects across the subarctic gyre and the subtropical gyre (Fig. 1) from the surface down to about $2000 \mathrm{~m}$ for turbulence and down to about $1000 \mathrm{~m}$ for nitrate. The rest of the paper is organized as follows: In Sect. 2, details of observations and data processing methods are presented. In Sect. 3, hydrographic cross-sections including nitrate concentration and its gradient, vertical diffusivity, and the vertical turbulent nitrate flux are presented. We also distinguish the contributions of the nitrate gradient and diffusivity to the nitrate flux. Finally, in Sect. 4, we compare the measured levels of turbulence and the nitrate flux with those of previous studies and discuss the influence of the vertical nitrate flux on the ecological biogeography of the western North Pacific. 


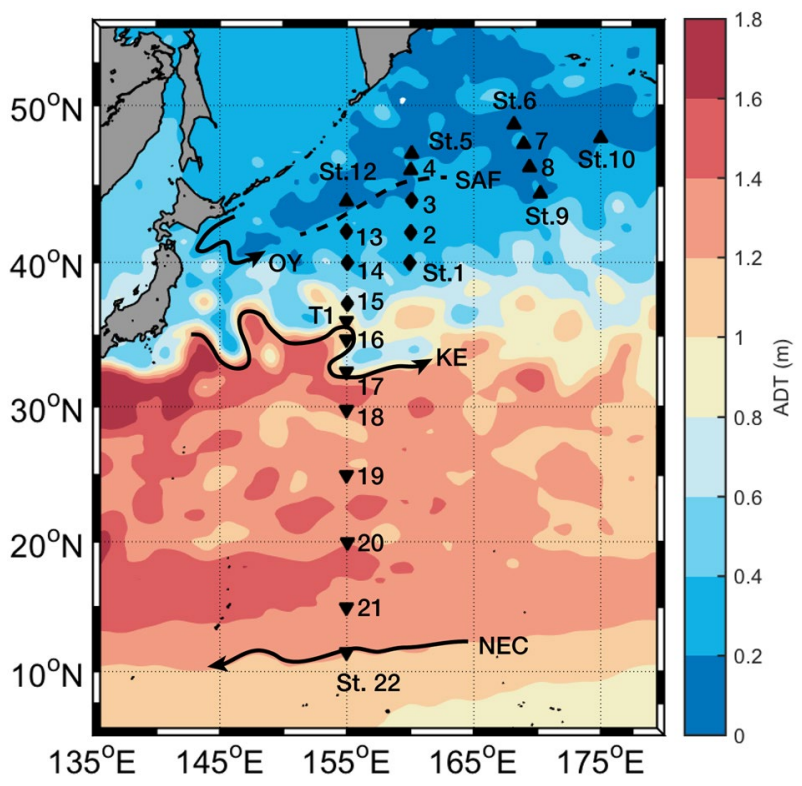

Fig. 1 Observation sites superposed on the monthly mean of absolute dynamic topography in August 2008. The absolute dynamic topography data were processed by Segment Sol multimissions d'ALTimetrie, d'Orbitographie et de localisation precise/Data Unification and Altimeter Combination System and distributed by Archiving, Validation, and Interpretation of Satellite Oceanographic Data (AVISO+, https://www.aviso.altimetry.fr/duacs/), with support from Centre National d'Études Spatiales. Up-pointing triangles, diamonds, and down-pointing triangles denote stations in the subarctic (including the Emperor Sea Mounts), the Kuroshio-Oyashio transition region, and subtropical region, respectively. $S A F$ subarctic front, $O Y$ the Oyashio, $K E$ the Kuroshio Extension, NEC North Equatorial Current

\section{Data and methods}

\subsection{Observations}

Observations were made during the KH-08-2 cruise of the R/V Hakuho-Maru (1 August to 9 September 2008) at 12 stations on a transect along $155^{\circ} \mathrm{E}\left(11.5^{\circ}-44^{\circ} \mathrm{N}\right), 5$ stations along $160^{\circ} \mathrm{E}\left(40^{\circ}-47^{\circ} \mathrm{N}\right), 4$ stations along the ESM, and 1 station east of the ESM $\left(48^{\circ} \mathrm{N}, 175^{\circ}\right.$ E) (Figs. 1, 2). At each station except for Sts. 2, 4, and 11 (Table 1), a vertical microstructure profiler (VMP2000; Rockland Scientific International Inc.) equipped with temperature and conductivity sensors (SBE3 and 4; SeaBird Electronics Inc.) was deployed down to almost $2000 \mathrm{dbar}$. Observations at $42^{\circ} \mathrm{N}$, $160^{\circ} \mathrm{E}$ were conducted twice to examine temporal change in surface chlorophyll $a$ on 2 and 15 August as Sts. 2 and 11 , respectively, but neither included turbulence measurements. There was also a specific VMP station, T1 $\left(36^{\circ} \mathrm{N}\right)$, on the $155^{\circ} \mathrm{E}$ line in addition to the 12 stations mentioned above (Fig. 1). Within a few hours of each VMP cast, conductivity-temperature-depth (CTD; SBE911plus; SeaBird

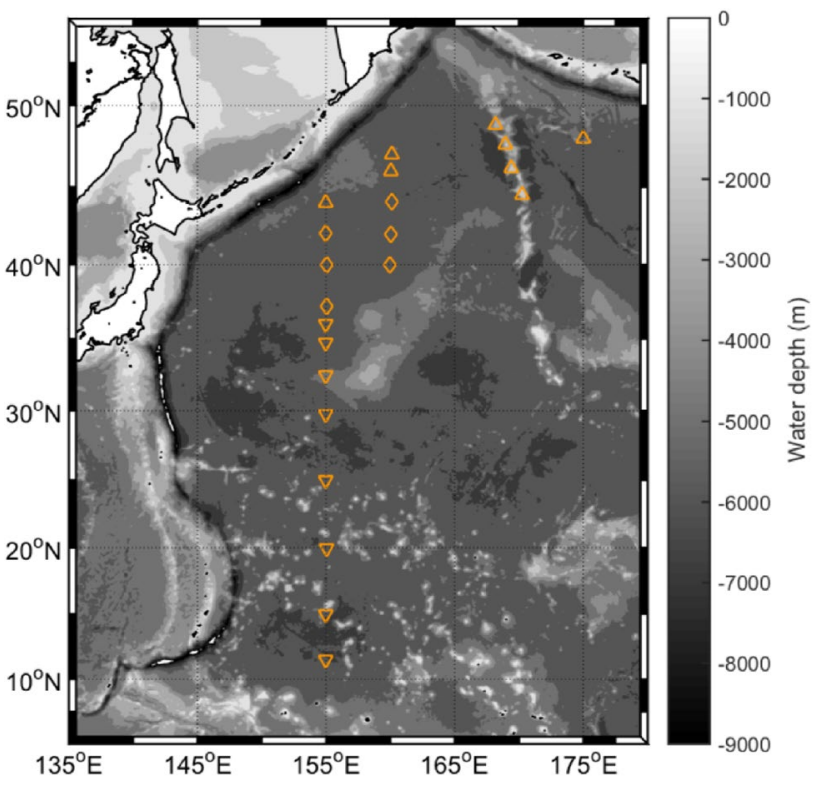

Fig. 2 Topography of the observation sites. Up-pointing triangles, diamonds, and down-pointing triangles denote stations in the subarctic (including the Emperor Sea Mounts), the Kuroshio-Oyashio transition region, and subtropical region, respectively

Table 1 Locations of the observational stations used in the present study

\begin{tabular}{lllll}
\hline Station & Latitude & Longitude & Region & Note \\
\hline St. 1 & $40^{\circ} \mathrm{N}$ & $160^{\circ} \mathrm{E}$ & KOTA & \\
St. 2 & $42^{\circ} \mathrm{N}$ & $160^{\circ} \mathrm{E}$ & KOTA & Without VMP observation \\
St. 3 & $44^{\circ} \mathrm{N}$ & $160^{\circ} \mathrm{E}$ & KOTA & \\
St. 4 & $46^{\circ} \mathrm{N}$ & $160^{\circ} \mathrm{E}$ & KOTA & Without VMP observation \\
St. 5 & $47^{\circ} \mathrm{N}$ & $160^{\circ} 5^{\prime} \mathrm{E}$ & SAG & \\
St. 6 & $48^{\circ} 50^{\prime} \mathrm{N}$ & $168^{\circ} 9^{\prime} \mathrm{E}$ & $\mathrm{ESM}$ & \\
St. 7 & $47^{\circ} 38^{\prime} \mathrm{N}$ & $168^{\circ} 58^{\prime} \mathrm{E}$ & $\mathrm{ESM}$ & \\
St. 8 & $46^{\circ} 10^{\prime} \mathrm{N}$ & $169^{\circ} 25^{\prime} \mathrm{E}$ & $\mathrm{ESM}$ & \\
St. 9 & $44^{\circ} 30^{\prime} \mathrm{N}$ & $170^{\circ} 15^{\prime} \mathrm{E}$ & $\mathrm{ESM}$ & \\
St. 10 & $48^{\circ} \mathrm{N}$ & $175^{\circ} \mathrm{E}$ & SAG & \\
St. 11 & $42^{\circ} \mathrm{N}$ & $160^{\circ} \mathrm{E}$ & KOTA & Revisit of St.2 \\
St. 12 & $44^{\circ} \mathrm{N}$ & $155^{\circ} \mathrm{E}$ & SAG & \\
St. 13 & $42^{\circ} \mathrm{N}$ & $155^{\circ} \mathrm{E}$ & KOTA & \\
St. 14 & $40^{\circ} \mathrm{N}$ & $155^{\circ} \mathrm{E}$ & KOTA & \\
St. 15 & $37^{\circ} 15^{\prime} \mathrm{N}$ & $155^{\circ} \mathrm{E}$ & KOTA & \\
T1 & $36^{\circ} \mathrm{N}$ & $155^{\circ} \mathrm{E}$ & KE & Without nitrate observation \\
St. 16 & $34^{\circ} 55^{\prime} \mathrm{N}$ & $155^{\circ} \mathrm{E}$ & KE & \\
St. 17 & $32^{\circ} 30^{\prime} \mathrm{N}$ & $155^{\circ} \mathrm{E}$ & KE & \\
St. 18 & $29^{\circ} 45^{\prime} \mathrm{N}$ & $155^{\circ} \mathrm{E}$ & STG & \\
St. 19 & $25^{\circ} \mathrm{N}$ & $155^{\circ} \mathrm{E}$ & STG & \\
St. 20 & $20^{\circ} \mathrm{N}$ & $155^{\circ} \mathrm{E}$ & STG & \\
St. 21 & $15^{\circ} \mathrm{N}$ & $155^{\circ} \mathrm{E}$ & STG & \\
St. 22 & $11^{\circ} 30^{\prime} \mathrm{N}$ & $155^{\circ} \mathrm{E}$ & NEC & \\
\hline
\end{tabular}

KOTA Kuroshio-Oyashio transition area, SAG subarctic gyre, ESM Emperor Sea mounts, $K E$ Kuroshio extension, $S T G$ subtropical gyre, $N E C$ North Equatorial Current 
Electronics Inc.) measurements and water samplings were carried out (except for station T1). A nitrate profiler (in situ ultraviolet spectrophotometer, ISUS; Satlantic Inc.), and a fluorometer (AQUAtracka 3; Chelsea Technologies Group Ltd.) were attached to the mounting frame of the CTD. ISUS observations were made from the surface down to $1000 \mathrm{dbar}$. Measurements of photosynthetically active radiation above $200 \mathrm{dbar}$ were also made using an Integrating Natural Fluorometer (INF-300; Biospherical Instruments Inc.) at Sts. $1-3,5,6,8-12,16$, and 20. In addition, expendable CTDs (XCTDs; Tsurumi Seiki Co., Ltd.) were deployed at every degree of latitude.

To distinguish the general hydrographic features of the above observation stations, we mapped the stations onto the absolute dynamic topography field. The absolute dynamic topography data with a horizontal interval of $1 / 4^{\circ}$ were processed by Segment Sol multimissions d'ALTimetrie, d'Orbitographie et de localisation precise (SSALTO)/Data Unification and Altimeter Combination System (DUACS) and distributed by Archiving, Validation, and Interpretation of Satellite Oceanographic Data (AVISO+; https:// www.aviso.altimetry.fr) with support from Centre National d'Études Spatiales (CNES) (Re3data.Org 2016; https://doi. org/10.17616/R3B332) (Fig. 1). We employed the 2-min Gridded Global Relief Data (ETOPO2v2) provided by the National Geophysical Data Center (NGDC), National Environmental Satellite, Data, and Information Service (NESDIS), National Oceanic and Atmospheric Administration (NOAA), US Department of Commerce (NGDC 2006: https ://www.ngdc.noaa.gov/mgg/fliers/06mgg01.html) as topographic data (Fig. 2).

\subsection{Data processing and analysis}

The ISUS measurements of nitrate concentration during the downcast of CTD surveys were used in the present study. The raw data of the downcasts obtained with a vertical interval of $1 \mathrm{dbar}$ were linearly adjusted to the nitrate concentration of the water samples taken during the upcasts. The limit of detection of the ISUS is $\sim 1.5 \mathrm{mmol} \mathrm{m}^{-3}$ (e.g., Johnson and Coletti 2002). Near the surface, we treated the nitrate concentration as $0 \mathrm{mmol} \mathrm{m}^{-3}$ at depths shallower than those where the concentration obtained from the water samples (around 0, 5, 10, 20, 30, 40, 50, 75, 100, 125, 150, and 200 dbar at each station) became smaller than $0.03 \mathrm{mmol} \mathrm{m}^{-3}$. Using the data obtained from water sampling, we also confirmed that these adjustments represented the distribution of nitrate, including the small gradient of nitrate around the depth of the base of the euphotic zone (as defined below), especially in the oligotrophic subtropical region. Chlorophyll $a$ fluorescence measured by the fluorometer was also linearly adjusted to the chlorophyll $a$ concentration of the water samples determined by a Turner Designs fluorometer
(Welschmeyer 1994). The base of the euphotic zone was defined as the depth where the photosynthetically active radiation was reduced to $1 \%$ of that at 5 dbar at Sts. $1-3,5,6$, $8-12,16$, and 20 . The depth of the base of the euphotic zone was also estimated using the method of Lee et al. (2007) for all stations.

We calculated turbulent kinetic energy dissipation rates $\varepsilon\left(\mathrm{W} \mathrm{kg}^{-1}\right)$ from microscale velocity measurements by the VMP using the same method as Kaneko et al. (2012), which yields $\varepsilon$ profiles with an approximate vertical resolution of $10 \mathrm{dbar}$. Vertical diffusivity $K_{\rho}\left(\mathrm{m}^{2} \mathrm{~s}^{-1}\right)$ was calculated from $\varepsilon$ and the squared buoyancy frequency $N^{2}\left(\mathrm{~s}^{-2}\right)$ as

$K_{\rho}=\Gamma \varepsilon / N^{2}$,

assuming a mixing efficiency $\Gamma=0.2$ (Osborn 1980).

Considering the intermittent nature of turbulence, we estimated the vertical turbulent nitrate flux $\overline{F_{N}}$ as follows, assuming that eddy diffusivity, $K_{\rho}$, is equivalent to the vertical diffusivity of nitrate, $K_{\mathrm{N}}$ :

$\overline{F_{\mathrm{N}}}=-\overline{K_{\rho}} \frac{\partial \overline{C_{\mathrm{N}}}}{\partial z}$,

where $C_{\mathrm{N}}$ indicates the nitrate concentration $\left(\mathrm{mmol} \mathrm{m}^{-3}\right)$ measured by the ISUS, and overbars denote averages over a 50-m grid-bin in the vertical direction. Here, since large variability would be expected because of the turbulence, we employed $50 \mathrm{~m}$ grid-bins based on the method of Kaneko et al. (2013) to improve the accuracy of the estimation. Note that $\overline{K_{\rho}}$ is calculated as follows:

$\overline{K_{\rho}}=\Gamma \bar{\varepsilon} / \overline{N^{2}}$.

Confidence intervals at the $95 \%$ level were also estimated using the bootstrap method. We calculated the $95 \%$ confidence levels for both the vertical diffusivity and the gradient of nitrate and compared their influence on the confidence level of the fluxes. The results showed that large variability in the diffusivity had more impact on the confidence level of the fluxes than that of the nitrate gradient (not shown). We then calculated the vertical flux divergence as the difference in flux between adjacent $50 \mathrm{~m}$ bins.

\subsection{Factors driving turbulence}

Tides and winds are the major forcing factors of turbulence. They enhance internal waves at tidal and near-inertial frequencies, as well as directly dissipating kinetic energy in the bottom and surface boundary layers, respectively. Thus, they were estimated for comparison with turbulence. As an indicator of the internal-tide forcing in the local region, we employed the $0.5^{\circ}$ resolution dataset of temporally and vertically averaged dissipation rate caused by the internal tide 
provided by de Lavergne et al. (2019), denoted as $D_{\text {tide }}$. As an indicator of the surface wind forcing in the local region, we estimated the local surface energy flux from the wind field as $E_{\text {wind }}$ following Oakey and Elliott (1982), that is,

$E_{\text {wind }}=\rho_{\mathrm{a}} C_{10} U_{10}^{3}$,

where $\rho_{\mathrm{a}}$ is the air density (taken as constant; $1.2 \mathrm{~kg} \mathrm{~m}^{-3}$ ), $C_{10}$ is the drag coefficient $\left(1.3 \times 10^{-3}\right)$, and $U_{10}$ is wind speed at $10 \mathrm{~m}$. We used the third-generation Japanese Ocean Flux Data Sets with Use of Remote Sensing Observations (J-OFURO3; Tomita et al. 2018; https://www.j-ofuro.scc.utokai.ac.jp) for analysis of the daily wind speed data at each VMP station. Note that although the energy from the wind dissipates in the mixing layer near the surface, some of the energy is transferred to the near-inertial waves and can affect dissipation within the interior of the ocean. It is also important to note that $E_{\text {wind }}$ does not represent the near-inertial waves generated by the frontal processes reported in previous studies (e.g., Alford et al. 2013; Nagai et al. 2015).

\section{Results}

\subsection{Hydrographic structure and the intensity of turbulence}

During the period of observation, the cyclonic subarctic gyre and the anticyclonic subtropical gyre were clearly recognized in the absolute dynamic topography field around the observational stations (Fig. 1). Along the $155^{\circ} \mathrm{E}$ transect, the northernmost station (St. 12) was located in the subarctic gyre, and the southernmost station (St. 22) was in the North Equatorial Current, which is the southern bound of the subtropical gyre (Table 1). It is noted that the southern stations (Sts. 19-22) in the subtropical gyre are located over the characteristic topography (Fig. 2). Stations 1-5 and 11 along the $160^{\circ} \mathrm{E}$ transect appear to be distributed from the subarctic gyre to the KOTA. The KE, generally referred to as the northern bound of the subtropical gyre, did not flow simply eastward but took a Z-shaped path around $155^{\circ}$ $\mathrm{E}$, and was thus observed in a relatively wide latitudinal range of $31^{\circ}-36^{\circ} \mathrm{N}$, where three stations ( $\mathrm{T} 1,16$, and 17 ) were located (Fig. 1). Here, the subarctic front and the KE were detected based on the temperature distribution $\left(4{ }^{\circ} \mathrm{C}\right.$ at $100 \mathrm{~m}$; Favorite et al. 1976 , and $14{ }^{\circ} \mathrm{C}$ at $200 \mathrm{~m}$; Kawai 1969, respectively; Fig. 3a-c). The four stations 6-9 along the ESM transect were located above the sea mounts with depths of 1150-2390 m (Fig. 2). (a)

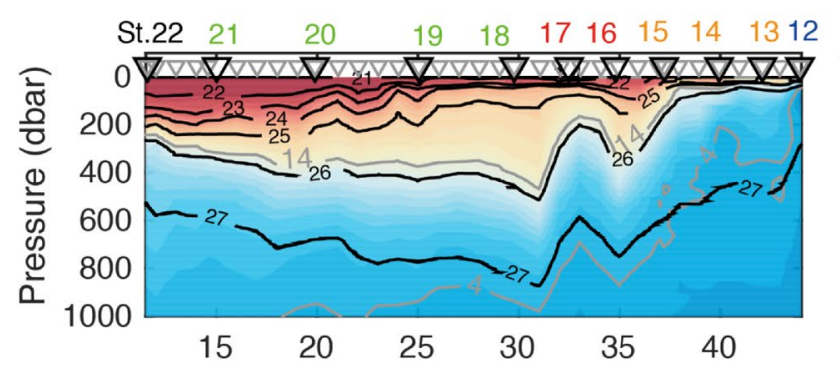

(d)

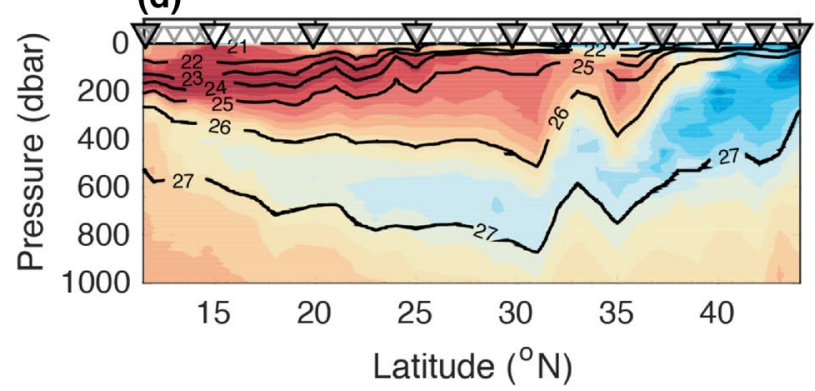

Fig. 3 Vertical cross-sections of $\mathbf{a}-\mathbf{c}$ potential temperature and $\mathbf{d}-\mathbf{f}$ salinity along the observational transect at $155^{\circ} \mathrm{E}$ (left column), $160^{\circ}$ E (middle column), and the Emperor Sea Mounts (right column). The (b)

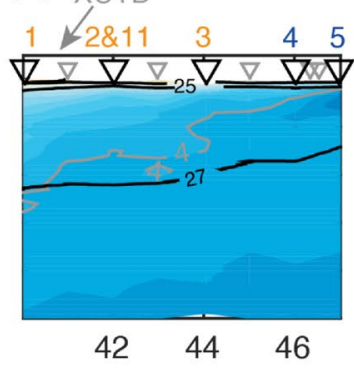

(e)

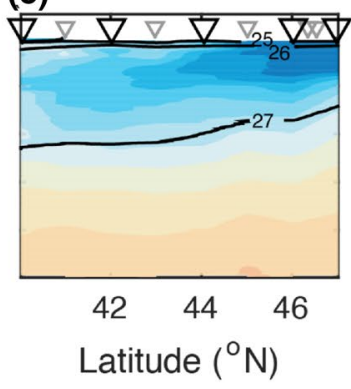

(c)
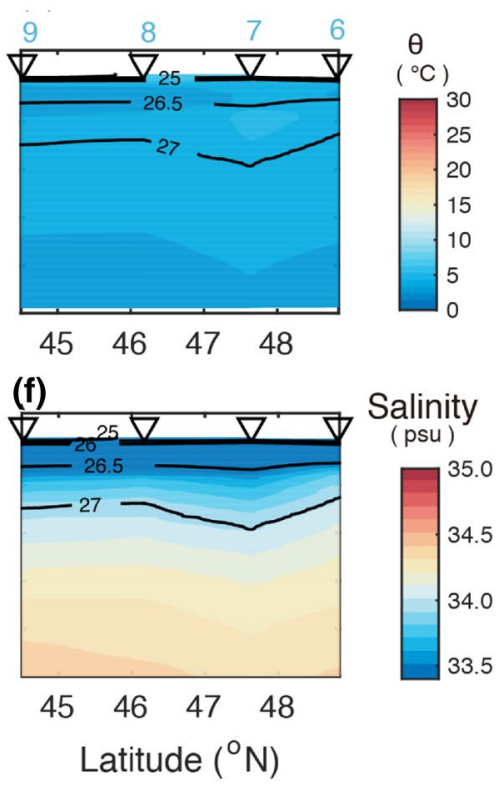

black and gray contours denote the potential densities and the potential temperature, respectively 
In addition to the properties at the above horizontal transects, stratifications of different water masses were also captured (Fig. 3). One of the most prominent features was the North Pacific Intermediate Water that is characterized by the vertical salinity minimum centered at $26.8 \sigma_{\theta}$ (Yasuda 1997). In the northern and middle parts of the subtropical gyre, from the KE $\left(\sim 36^{\circ} \mathrm{N}\right.$, just south of the axis) to $\sim 19^{\circ} \mathrm{N}$, a thick layer (i.e., a pycnostad) at 25.0-25.5 $\sigma_{\theta}$ (Fig. 3d) was observed above the North Pacific Intermediate Water, suggesting subtropical mode water (Masuzawa 1969). A shallow pycnocline was observed within the North Pacific Tropical Water (Cannon 1966), characterized by high salinity in layers around 24.0 $\sigma_{\theta}$; this occurred in the southern part of the subtropical gyre from $\sim 24^{\circ} \mathrm{N}$ to the North Equatorial Current $\left(\sim 11^{\circ}\right.$ N) (Fig. 3d).
The turbulent kinetic energy dissipation rate $\varepsilon$ was elevated near the surface $\left(>10^{-8} \mathrm{~W} \mathrm{~kg}^{-1}\right.$; Figs. 4, $5)$, around the shallow $\left(22.0-25.0 \quad \sigma_{\theta}\right)$ and the deep (26.0-27.0 $\left.\sigma_{\theta}\right)$ pycnoclines $\left(10^{-9}\right.$ to $10^{-8} \mathrm{~W} \mathrm{~kg}^{-1}$; Fig. 5), and over almost the whole water column in the ESM area $\left(10^{-9}\right.$ to $10^{-8} \mathrm{~W} \mathrm{~kg}^{-1}$; Figs. $\left.4 \mathrm{~b}, 5 \mathrm{c}\right)$, compared with $\varepsilon \sim 10^{-10} \mathrm{~W} \mathrm{~kg}^{-1}$ observed in other layers. The elevation near the pycnoclines was not continuous but was observed intermittently with a vertical scale of $<20 \mathrm{~m}$ (dbar), such as in the KOTA and KE (Sts. 15, T1, and 16; depth range of 200-500 dbar). Mid-depth enhancement of the dissipation was also seen beneath St. 19 at depths of 400-800 dbar (Figs. 4e, 5a). The elevations at mid-depth in the KE and subtropical gyre were consistent with those reported by Moum and Osborn (1986) along a section at $152^{\circ}$ E. Enhanced turbulence in the ESM area was observed (a) SAG

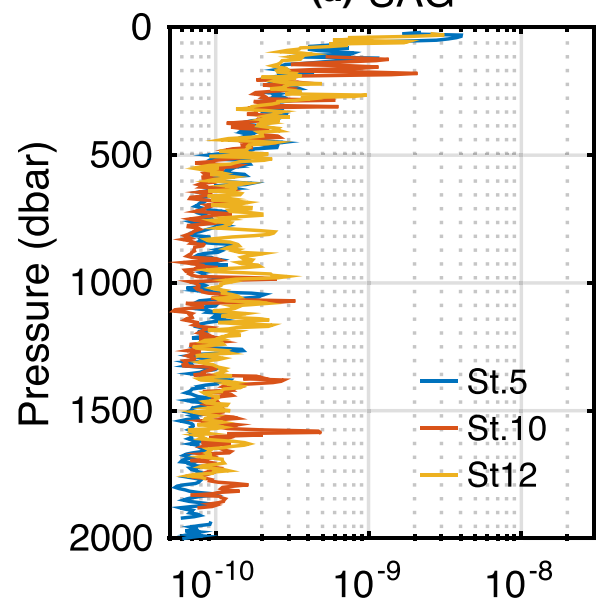

(d) $\mathrm{KE}$

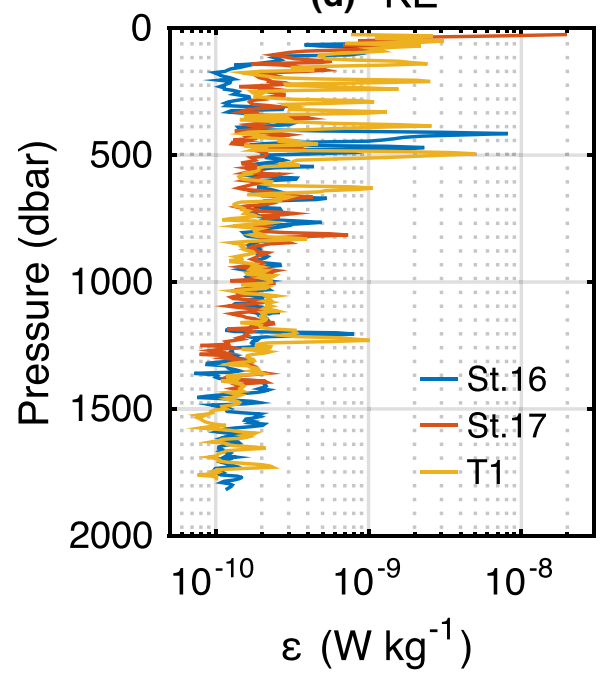

(b)ESM

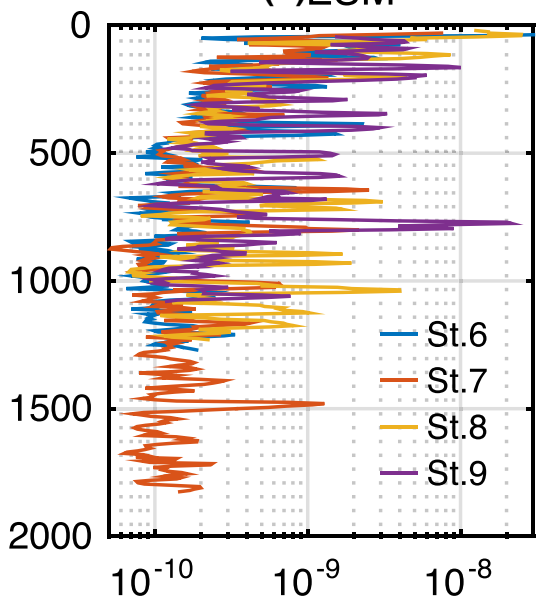

(e) STG

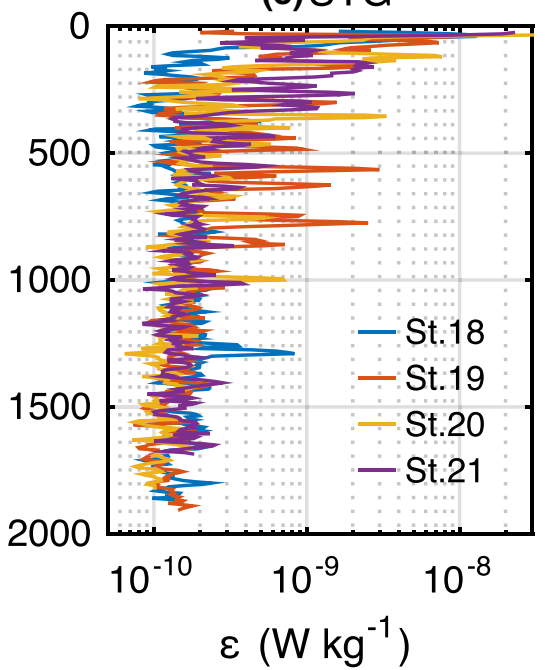

(c) KOTA

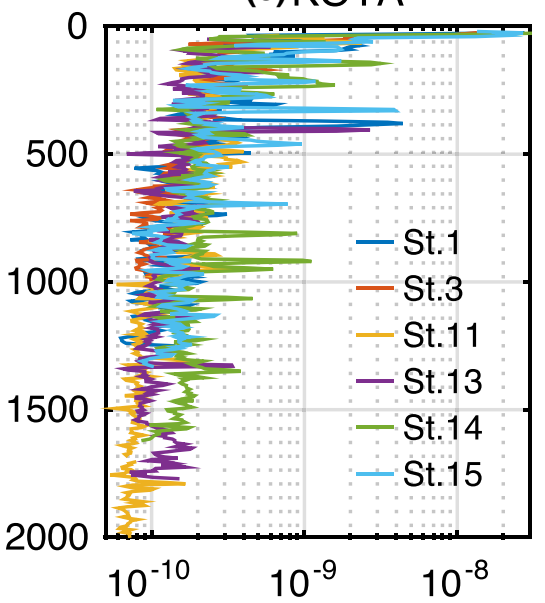

(f) NEC

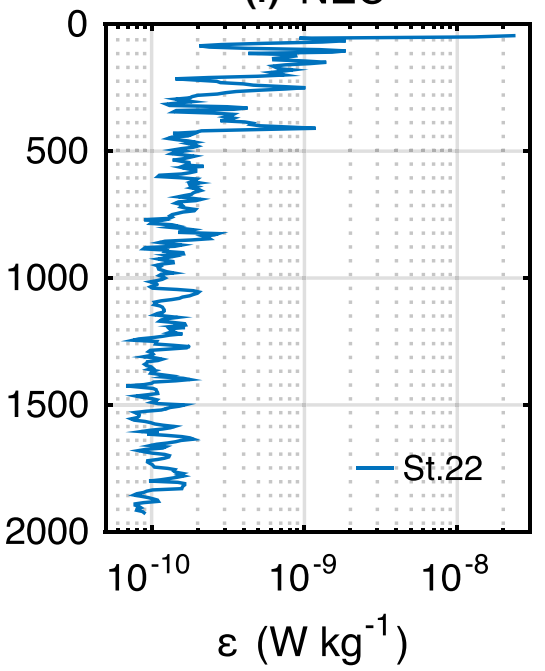

Fig. 4 Vertical profiles of dissipation rate in a subarctic gyre, b Emperor Sea Mounts, $\mathbf{c}$ Kuroshio-Oyashio transition region, $\mathbf{d}$ Kuroshio extension, e subtropical gyre, and $\mathbf{f}$ North Equatorial Current 
(a)

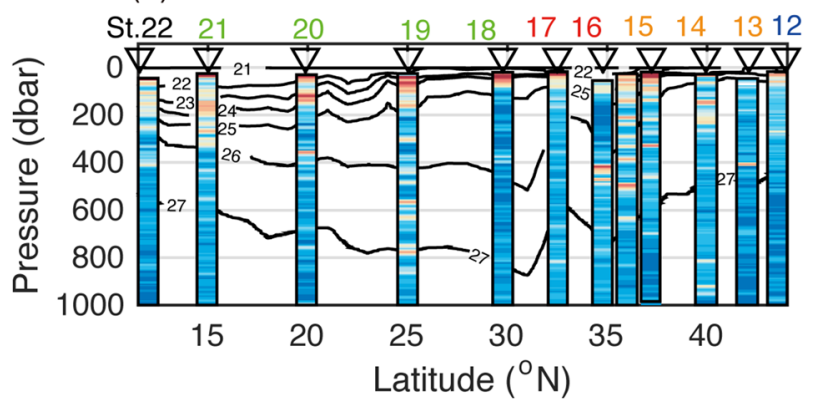

(b)

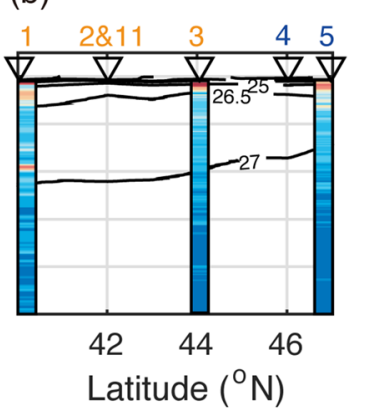

(c)

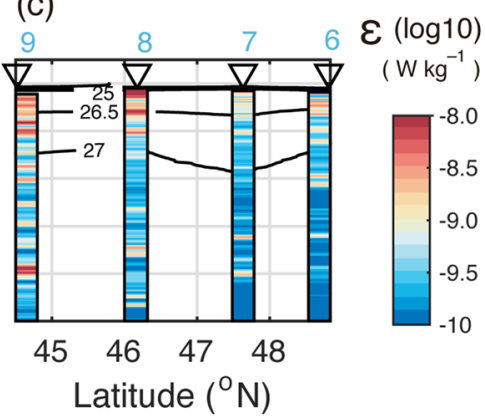

Fig. 5 Vertical distributions of dissipation rate along the $\mathbf{a} 155^{\circ} \mathrm{E}, \mathbf{b} 160^{\circ} \mathrm{E}$, and $\mathbf{c}$ Emperor Sea Mounts transects. Contours in $\mathbf{a}-\mathbf{c}$ are potential density

over a relatively wide range, such as in the pycnocline $\left(>5 \times 10^{-9} \mathrm{~W} \mathrm{~kg}^{-1}\right.$ at $100-300 \mathrm{dbar}$ for Sts. 8 and 9; Figs. $4 \mathrm{~b}, 5 \mathrm{c}$ ) and at $\sim 800 \mathrm{dbar}$ far below the pycnocline (St. 9), which might have been caused by internal wave radiation from the sea mounts (Nagasawa et al. 2007). Isolated enhancement of turbulence was also observed at depths deeper than $1000 \mathrm{dbar}$ at St. 10 in the subarctic gyre ( 1600 dbar, Fig. 4a), at St. 16 and 17 in the KE $(\sim 1250$ dbar, Fig. 4 d) , and at St. 18 in the subtropical gyre ( 1300 dbar, Fig. 4e), possibly showing intermittent breaking of internal waves.

Vertical diffusivity was generally enhanced at the depths where turbulence enhancement occurred, except for the subsurface pycnocline (Figs. 6, 7). In the ESM area, diffusivity was elevated at depths shallower than $1000 \mathrm{dbar}$ from a base level of $O\left(10^{-5}\right) \mathrm{m}^{2} \mathrm{~s}^{-1}$ (Fig. 6). Prominent peaks of diffusivity were observed at 1200 dbar beneath St. 8, and at 750 dbar and 1100 dbar beneath St. 9 (Fig. 6). The depths of the enhanced diffusivity corresponded to those where the dissipation was enhanced. At mid-depths (300-500 dbar) in the KE, diffusivity was also elevated $\left(\sim 10^{-5} \mathrm{~m}^{2} \mathrm{~s}^{-1}\right)$ (Figs. 6, 7a). At $150-250$ dbar for St. 14 (KOTA), elevated diffusivity $\left(5-10 \times 10^{-6}\right.$ $\mathrm{m}^{2} \mathrm{~s}^{-1}$ ) was correlated with the enhancement of the dissipation. Along the $155^{\circ} \mathrm{E}$ section, although the intense pycnocline reduced the diffusivity level to $1-3 \times 10^{-6}$ $\mathrm{m}^{2} \mathrm{~s}^{-1}$, with the exception of enhanced dissipation in the North Pacific Tropical Water (e.g., St. 20, 150 dbar, Fig. 7a), a general trend of diffusivity elevation at middepth $\left(0.3-1 \times 10^{-5} \mathrm{~m}^{2} \mathrm{~s}^{-1}\right)$ was obvious at each station, suggesting the effect of weak stratification. At depths greater than 1000 dbar, diffusivity was estimated as $O\left(10^{-5}\right) \mathrm{m}^{2} \mathrm{~s}^{-1}$ in all regions except for the ESM (Fig. 6). This level of $10^{-5} \mathrm{~m}^{2} \mathrm{~s}^{-1}$ is consistent with the level of diffusivity in the open ocean $O\left(10^{-5}\right) \mathrm{m}^{2} \mathrm{~s}^{-1}$ suggested by previous studies (Lewis et al. 1986; Gregg 1987; Ledwell et al. 1993; Waterhouse et al. 2014).

\subsection{Nitrate flux and chlorophyll a concentrations}

Nitrate distribution resembled that of density, with the well-known contrast between oligotrophic subtropical and non-oligotrophic subarctic waters in the near surface (Fig. 8a-c). In the KE, the local downward concave nitrate distribution associated with isopycnals occurred at depths deeper than $200 \mathrm{dbar}$ (along $26.0 \sigma_{\theta}$ ) around $35^{\circ} \mathrm{N}$ (Fig. 8a). In addition to the large-scale bowl-shaped vertical maximum at mid-depths $\left(26.0-27.0 \sigma_{\theta}\right.$ along $\left.155^{\circ} \mathrm{E}\right)$, the vertical gradients of nitrate were characterized by nitraclines at the subsurface along the 24.0-25.0 $\sigma_{\theta}$ isopycnals from the KE to the center of the subtropical gyre (Fig. 8d). The depth of the subsurface nitracline with a vertical gradient of nitrate exceeding $0.05 \mathrm{mmol} \mathrm{m}^{-4}$ increased with decreasing latitude. The mid-depth nitracline in the subtropical gyre situated at 400-800 dbar was associated with the vertical salinity minimum corresponding to the North Pacific Intermediate Water. The intensity of the nitracline around 26.5 $\sigma_{\theta}$ exceeded $0.1 \mathrm{mmol} \mathrm{m}^{-4}$ in the subarctic region, including the ESM (Fig. 8e, f).

Turbulent nitrate flux was generally markedly elevated around the nitraclines (Fig. 9a-c). In the ESM, elevated fluxes reaching $10^{-6} \mathrm{mmol} \mathrm{m}^{-2} \mathrm{~s}^{-1}$ were present at $50-300$ dbar where there was an intense nitracline $\left(>0.1 \mathrm{mmol} \mathrm{m}^{-4}\right)$ and enhanced $\overline{K_{\rho}}$ (Figs. 7c, 9c). In the KE and the KOTA, elevated fluxes frequently appeared around both subsurface and mid-depth nitraclines (Fig. 9a, b); for example, beneath St. 15, fluxes of $0.3-1 \times 10^{-6} \mathrm{mmol} \mathrm{m}^{-2} \mathrm{~s}^{-1}$ at 50-100 dbar, $1 \times 10^{-7} \mathrm{mmol} \mathrm{m}^{-2} \mathrm{~s}^{-1}$ at 150-200 dbar, and $0.3-1 \times 10^{-6} \mathrm{mmol} \mathrm{m}^{-2} \mathrm{~s}^{-1}$ at $250-500$ dbar. In addition, beneath St. 14, fluxes of $0.3-1 \times 10^{-6} \mathrm{mmol} \mathrm{m}^{-2} \mathrm{~s}^{-1}$ at 50-100 dbar and 150-300 dbar were observed. These elevations at greater depths occurred in the upper layer of North Pacific Intermediate Water (Fig. 9a). At St. 18, although the flux was small $\left(O\left(10^{-8}\right) \mathrm{mmol} \mathrm{m}^{-2} \mathrm{~s}^{-1}\right)$ in the interior 
(a) SAG

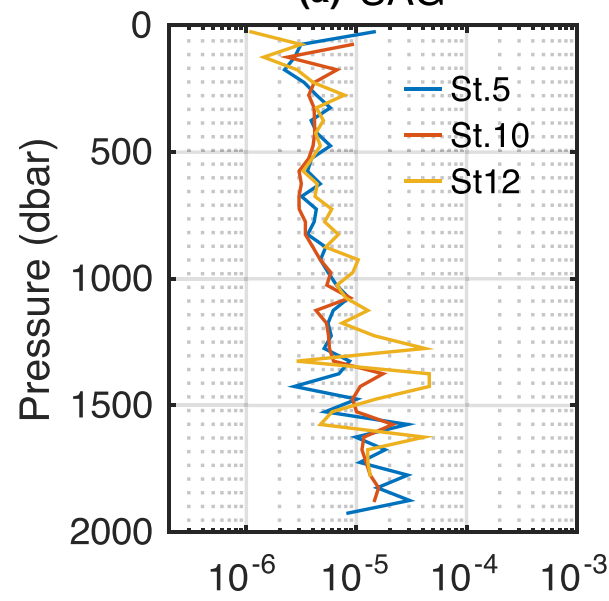

(d) $\mathrm{KE}$

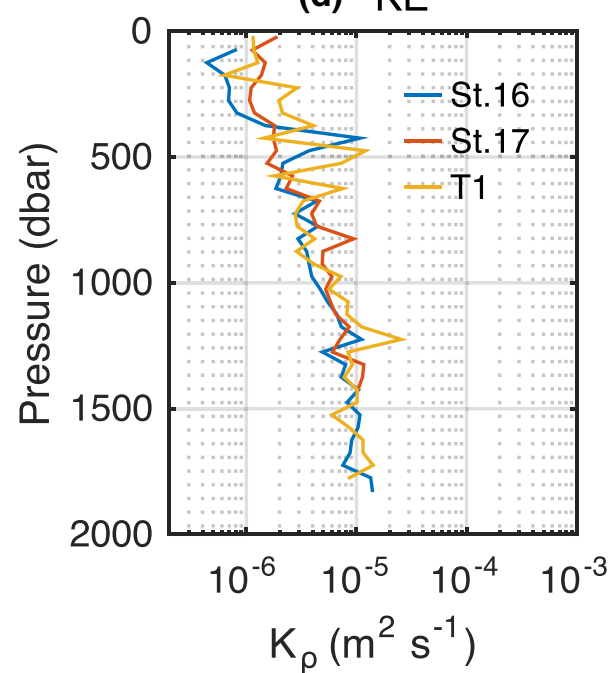

(b) ESM

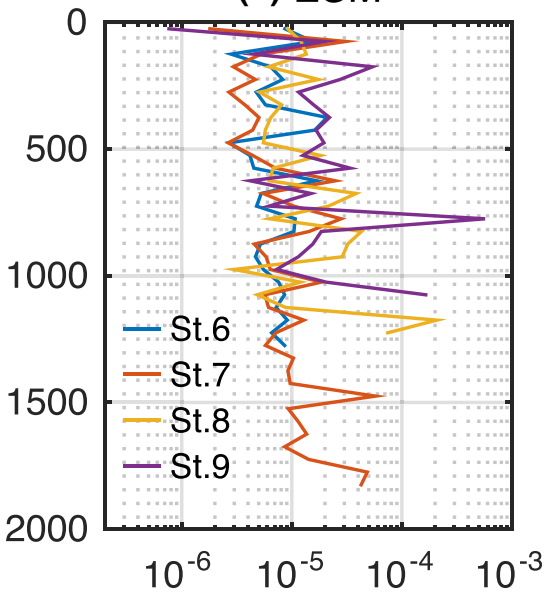

(e) STG

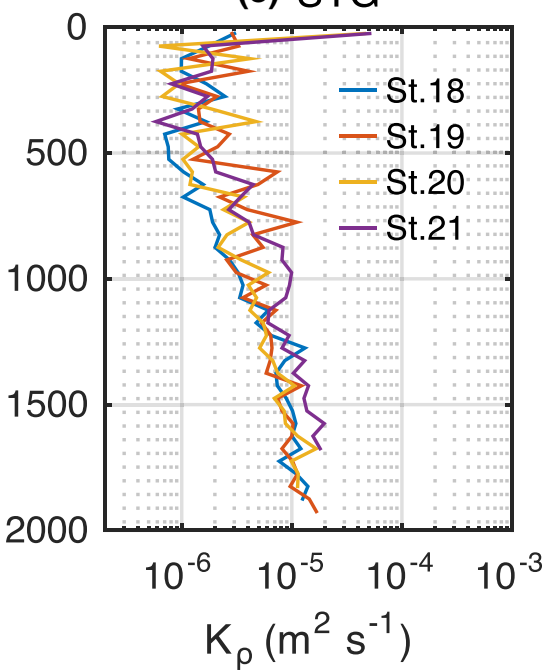

(c) KOTA

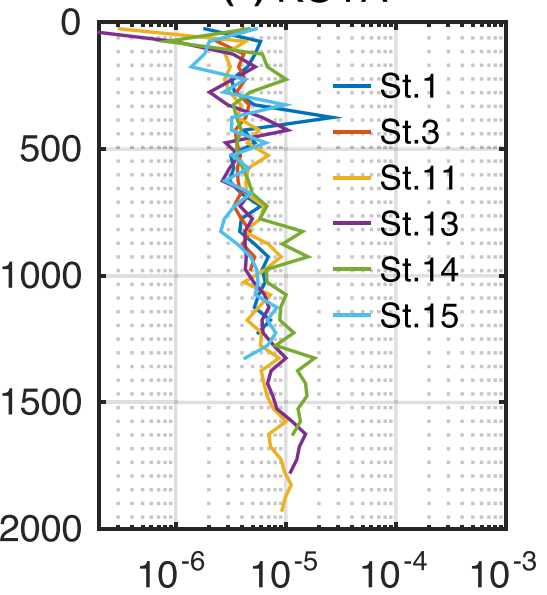

(f) NEC

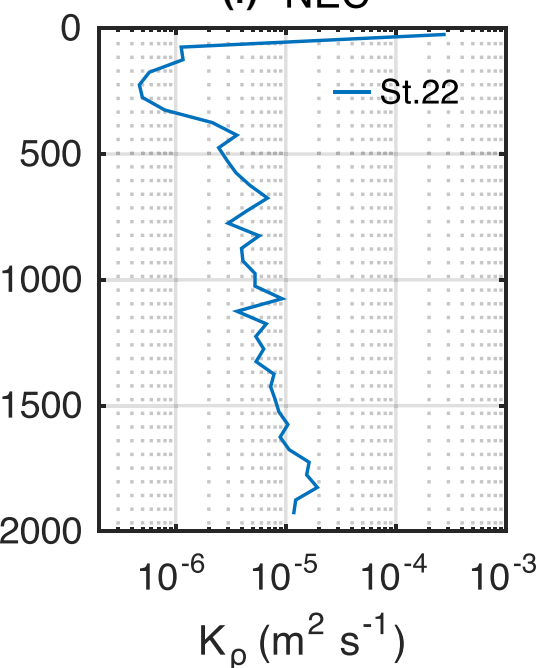

Fig. 6 As in Fig. 4, but for vertical diffusivity

(a)

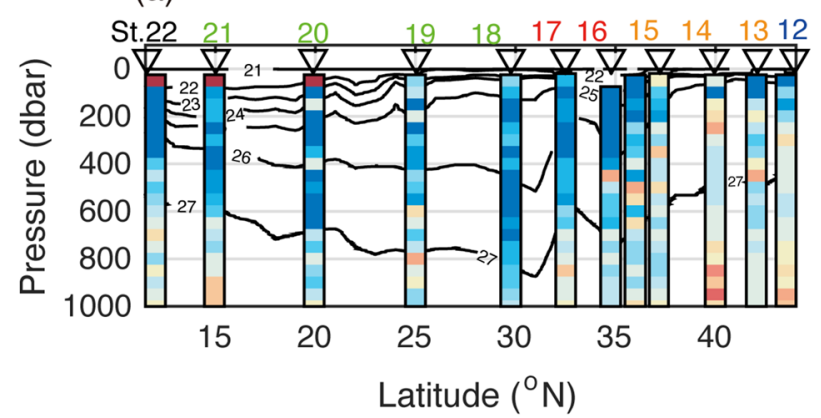

(b)

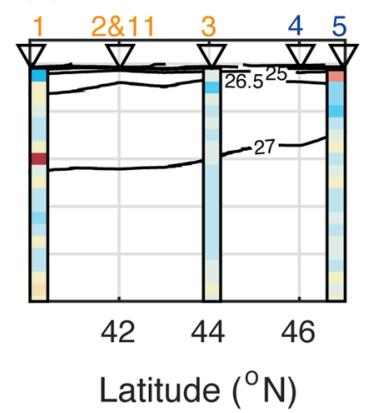

(c)

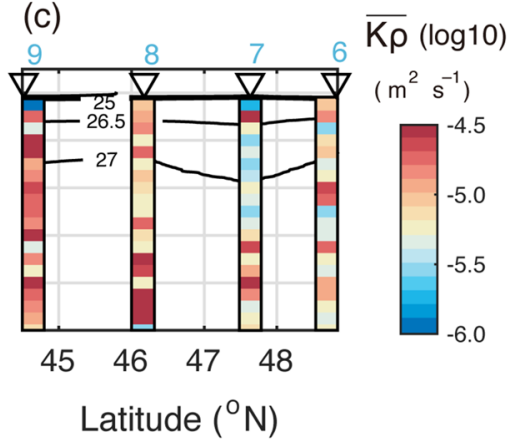

Fig. 7 As in Fig. 5, but for vertical diffusivity. Contours in $\mathbf{a}-\mathbf{c}$ are potential density

(200-300 dbar) of the subtropical mode water, enhancement up to $O\left(10^{-7}\right) \mathrm{mmol} \mathrm{m} \mathrm{m}^{-2} \mathrm{~s}^{-1}$ occurred in the upper part of the subtropical mode water (100-150 dbar) corresponding to the nitracline (Fig. 9a). 
(a)

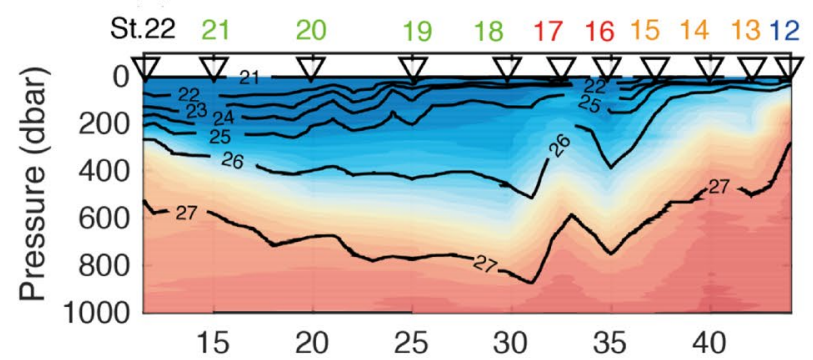

(d)

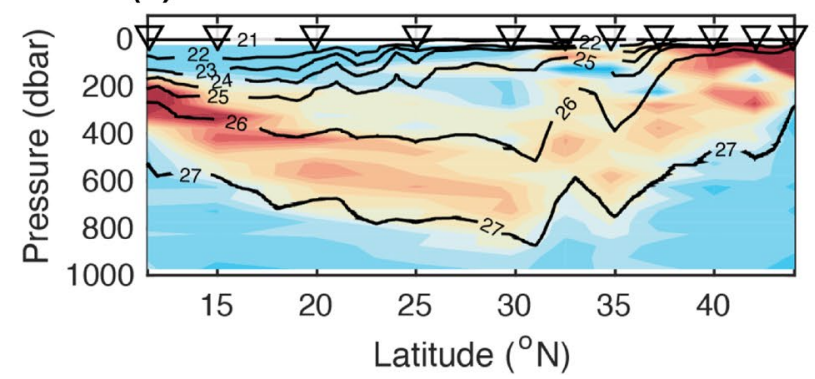

(b)

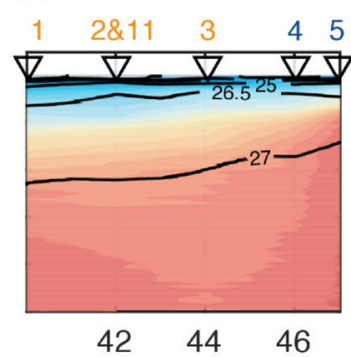

(e)

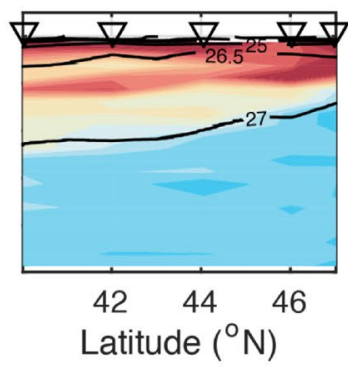

(c)

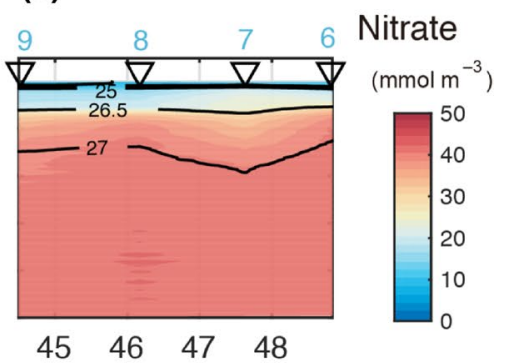

(f)

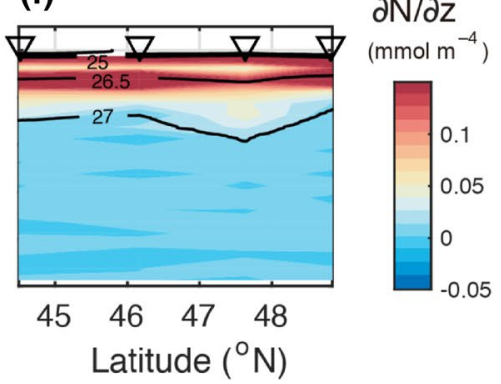

Fig. 8 As in Fig. 3, but for $\mathbf{a}-\mathbf{c}$ nitrate and $\mathbf{d}-\mathbf{f}$ vertical gradient of nitrate. Contours in a-f are potential density

(a)

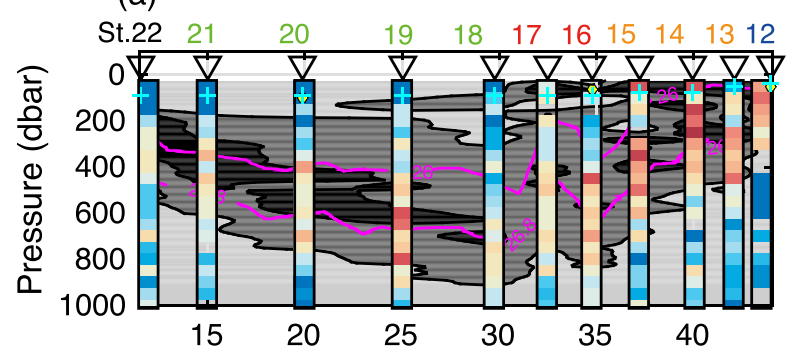

(d)

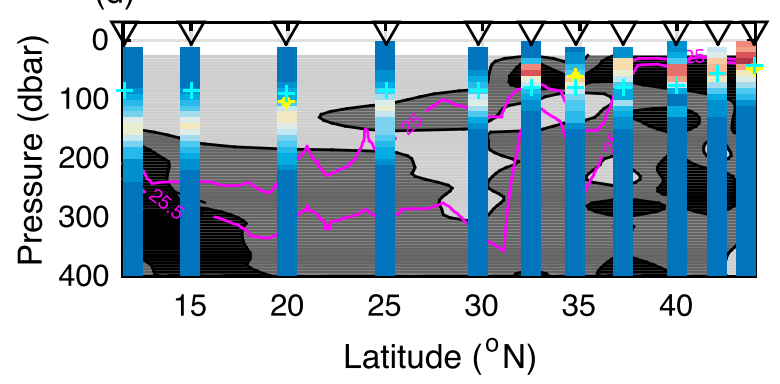

Fig. 9 As in Fig. 5, but for a-c turbulent nitrate flux and $\mathbf{d}-\mathbf{f}$ chlorophyll $a$ concentration. Shading denotes the vertical gradient of nitrate. Magenta contours indicate potential density. Yellow and cyan

Chlorophyll $a$ enhancement frequently occurred at the depth just above the subsurface nitracline around the base of the euphotic zone (except for the southern subtropical gyre), indicating the oligotrophic $\left(\sim 0.3 \mathrm{mg} \mathrm{m}^{-3}\right)$ and nonoligotrophic regions ( $\sim 0.5 \mathrm{mg} \mathrm{m}^{-3}$ or more) in the subtropical gyre and subarctic gyre, respectively (Fig. 9d-f). (b)

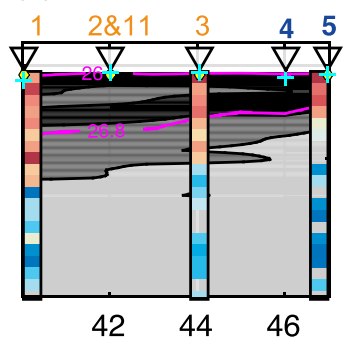

(e) St.2 (8/2) St.11 (8/15)

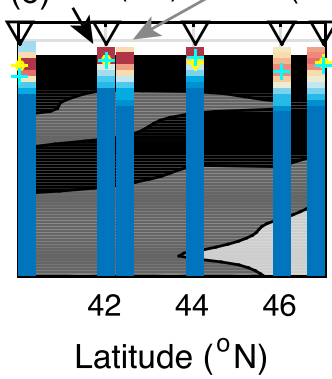

(c)
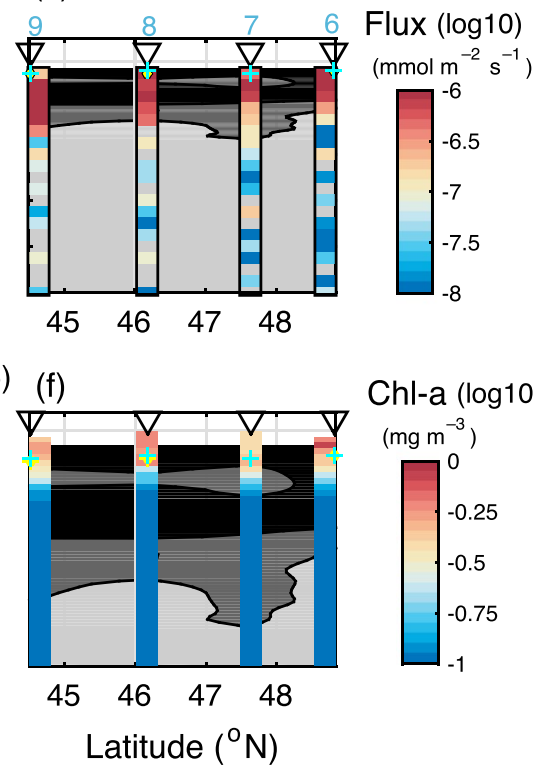

markers denote euphotic layer depths estimated from photosynthetically active radiation and the method of Lee et al. (2007), respectively (color figure online)

In addition to that found in the subarctic gyre, a high concentration of chlorophyll $a\left(>0.5 \mathrm{mg} \mathrm{m}^{-3}\right)$ was observed in the KOTA (Fig. 9d, e). A similar concentration to that in the KOTA $\left(0.5 \mathrm{mg} \mathrm{m}^{-3}\right)$ was also recognized at Sts. $16-17$ in the KE (Fig. 9d). Chlorophyll $a$ elevation was observed as a subsurface chlorophyll $a$ maximum, especially south of the 

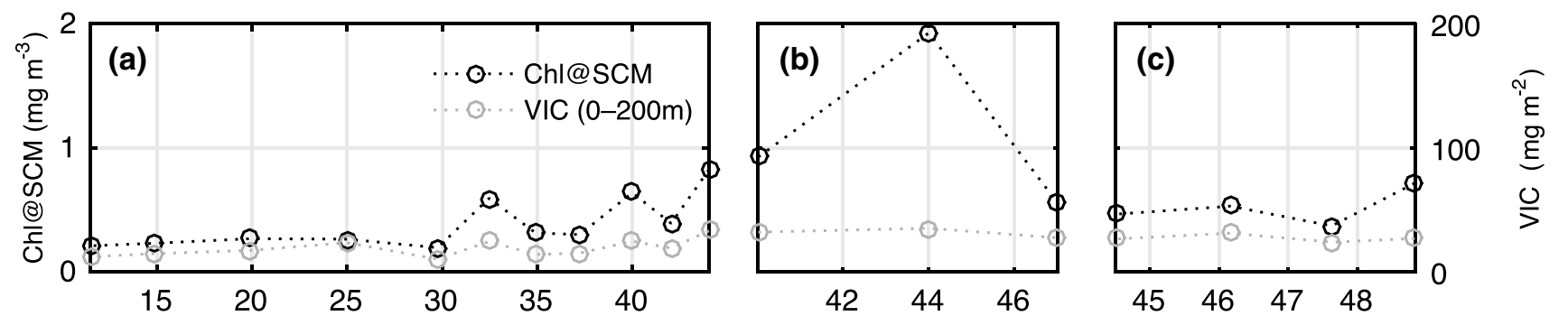

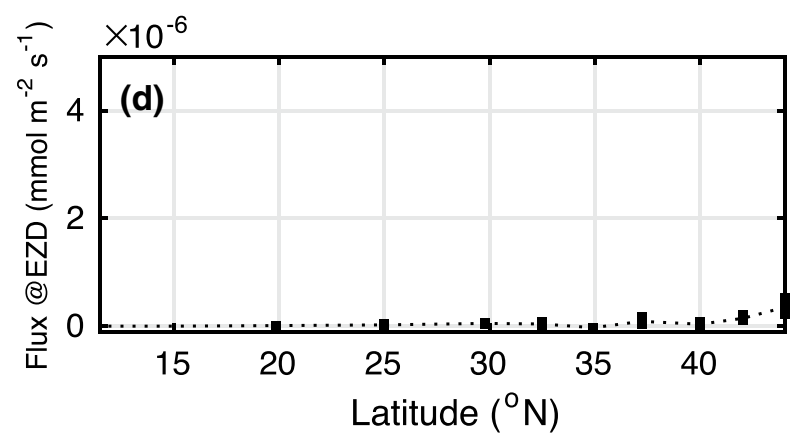

Fig. 10 Latitudinal distributions of a-c chlorophyll $a$ concentration at its subsurface maximum (SCM) and vertically integrated chlorophyll $a$ and $\mathbf{d}-\mathbf{f}$ turbulent nitrate fluxes at the euphotic zone depth (EZD).

KOTA. The highest value (almost $2 \mathrm{mg} \mathrm{m}^{-3}$ ) was observed in the KOTA (St. 3) (Fig. 10a-c). The vertically integrated chlorophyll $a$ concentration was also higher in the subarctic gyre than in the subtropical gyre, consistent with that at the subsurface chlorophyll $a$ maximum (Fig. 10a-c). The magnitude of the vertically integrated chlorophyll $a$ concentration in the KOTA was at a similar level to that in the subarctic gyre, suggesting prominent peaks of chlorophyll $a$ concentration at the subsurface chlorophyll $a$ maximum in the region (e.g., St. 3).
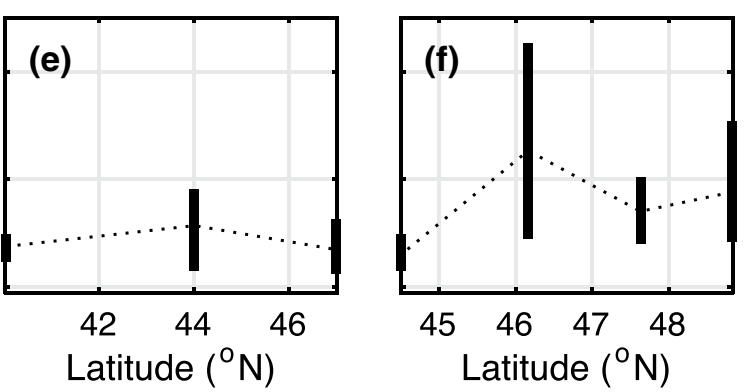

Error bars indicate $95 \%$ confidence intervals. VIC means vertically integrated chlorphyll $a$.

\subsection{Vertical flux at the base of the euphotic zone}

There was a large contrast in fluxes at the base of the euphotic zone between the subtropical gyre and other regions (Fig. 10d-f). In the subtropical gyre, the fluxes were estimated as $O\left(10^{-8}\right) \mathrm{mmol} \mathrm{m}^{-2} \mathrm{~s}^{-1}$ or smaller, owing to the weak vertical gradient of nitrate (Fig. 9a). The small gradient of nitrate was also confirmed by the nitrate concentrations obtained from water sampling in the subtropical gyre. In contrast to the small fluxes in the subtropical gyre, in the subarctic gyre, the fluxes were $O\left(10^{-7}\right) \mathrm{mmol} \mathrm{m}^{-2} \mathrm{~s}^{-1}$. In the ESM, although their magnitude varied considerably, the fluxes were $O\left(10^{-6}\right) \mathrm{mmol} \mathrm{m}^{-2} \mathrm{~s}^{-1}$. Fluxes in the KOTA
Fig. 11 Scatter plot of a vertical gradient of nitrate and turbulent nitrate fluxes and $\mathbf{b}$ vertical diffusivity and turbulent nitrate fluxes, at the euphotic zone depth (EZD). Error bars denote $95 \%$ confidence interval
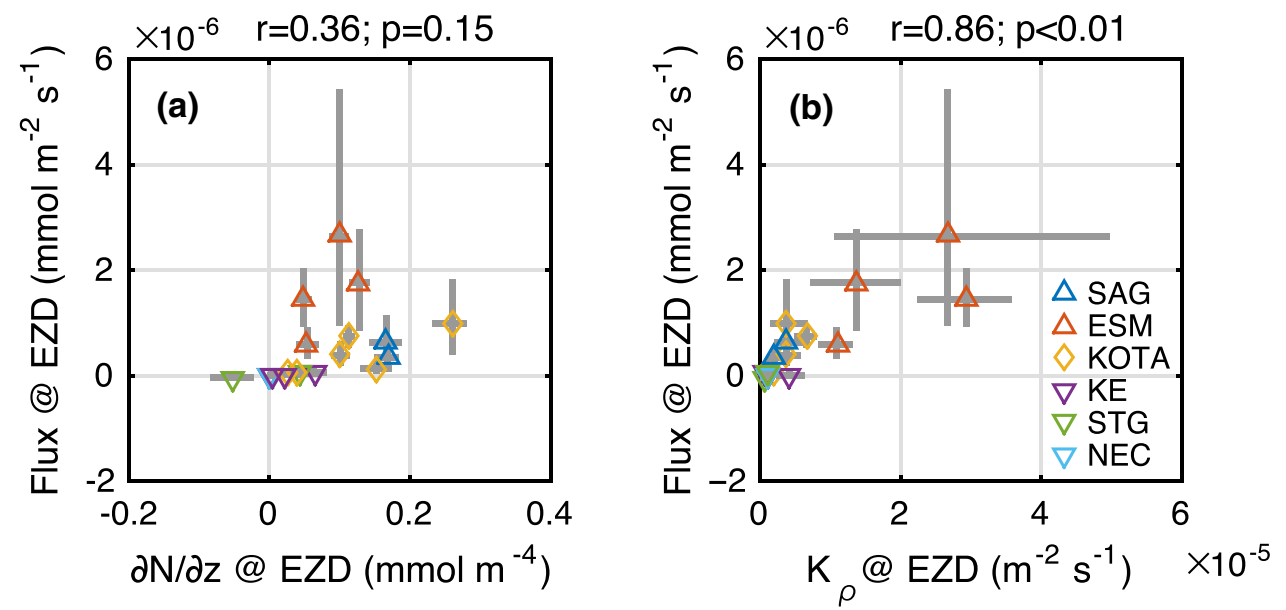
were at the same level as in the subarctic gyre, $O\left(10^{-7}\right)$ $\mathrm{mmol} \mathrm{m} \mathrm{s}^{-2} \mathrm{~s}^{-1}$. The relationship between the fluxes and the vertical gradient of nitrate at the base of the euphotic zone (Fig. 11a) was more ambiguous ( $r=0.36, p=0.15)$ than that between the fluxes and diffusivity, where significant correlation $(r=0.84, p<0.01)$ was found (Fig. 11b), suggesting a large contribution from the diffusivity to the fluxes. In particular, high diffusivities in the ESM corresponded to large fluxes. Although fluxes at the base of the euphotic zone did not show a significant relationship with the subsurface chlorophyll $a$ maximum concentration when all stations were considered, the relationship became clearer $(r=0.45$, $p=0.096$, Fig. 12a) when Sts. 3 and 11 were excluded. Note that there is a possibility of missing flux enhancement due to short-term mixing when only a single measurement of turbulence is made, which might lead to the ambiguous relationship when all stations are considered. In addition, at Sts. 3 and 11 , a prominent chlorophyll $a$ maximum was observed almost at the surface (Fig. 9e), suggesting that a prominent near-surface bloom occurred associated with a near-surface nitracline. At the repeated station (Sts. 2 and 11), the nearsurface chlorophyll $a$ peak disappeared rapidly and became a subsurface chlorophyll $a$ maximum in the 2 weeks (Fig. 9e).
Although the cause of such a prominent subsurface chlorophyll $a$ maximum remains unclear, such a surface bloom in the KOTA might affect the relationship between the fluxes and subsurface chlorophyll $a$ maximum concentration.

In the case of the vertically integrated chlorophyll $a$ concentration, a moderate relationship was obtained $(r=0.43$, $p=0.082$, Fig. 12b). The relationship between the fluxes and the vertically integrated chlorophyll $a$ concentration might indicate a longer-term contribution of vertical fluxes to the near-surface production as a result of the accumulation of nutrient supply from the deeper layer to the surface and subsequent production in the euphotic zone, assuming that the level of fluxes remains the same. The result showed mitigation of outliers in the KOTA, compared with those shown in Fig. 12a. This suggests the importance of verifying the time-scale of observations in future work for more accurate estimation, especially in the KOTA. In conclusion, for the present observations, although there was not such a clear linear relationship between the fluxes and chlorophyll $a$ concentration when all stations were considered, the contrast between the subtropical and the subarctic gyres including the ESM were substantial (Fig. 10).

Fig. 12 Plots of turbulent nitrate fluxes against a chlorophyll $a$ concentration at subsurface maximum (SCM) and b vertically integrated chlorophyll $a$ (VIC). Error bars denote $95 \%$ confidence intervals
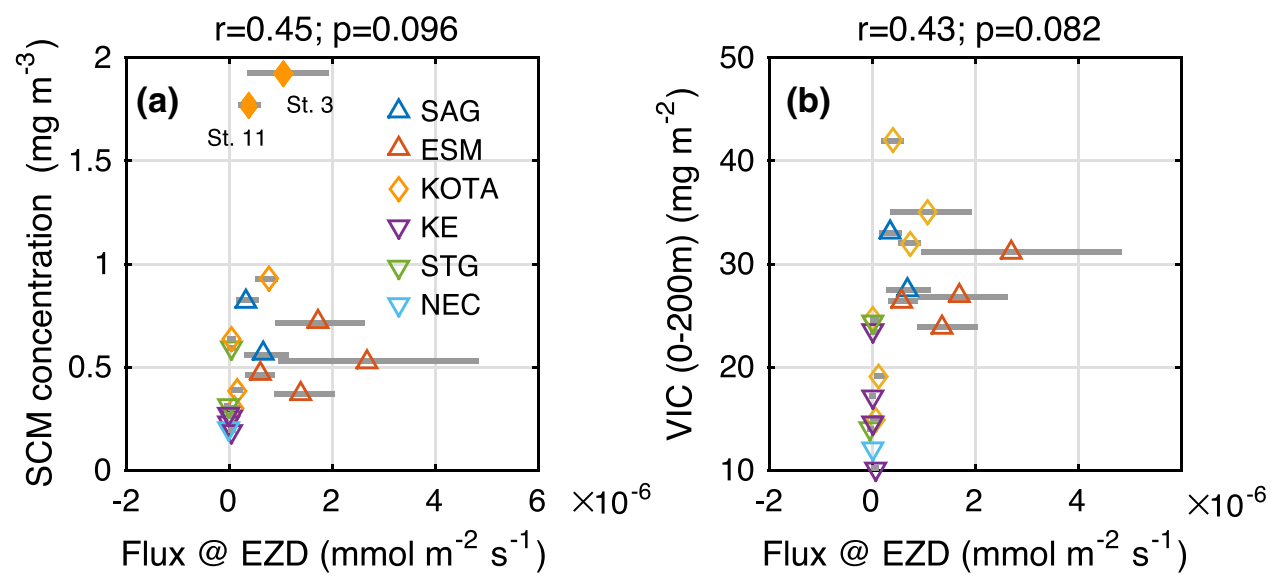

(a)

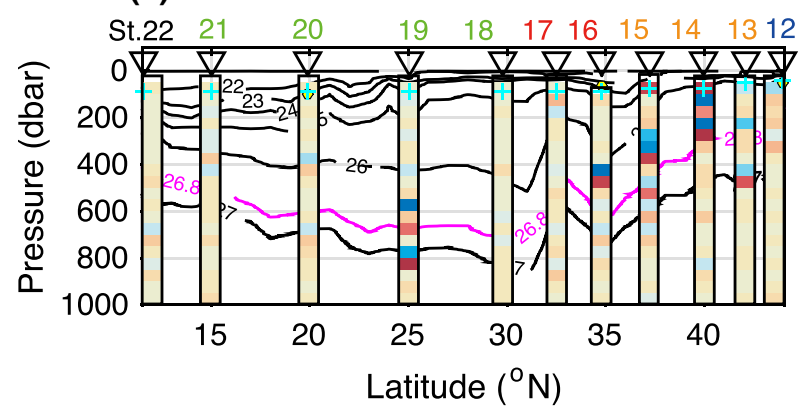

(b)

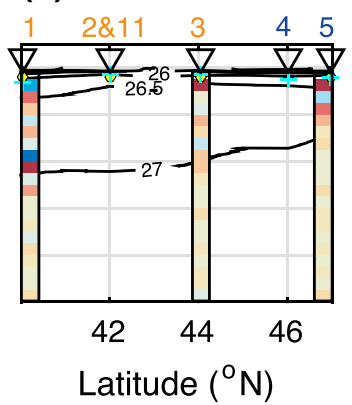

(c)

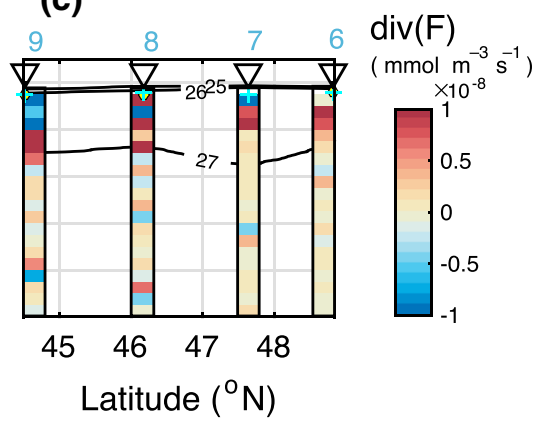

Fig. 13 As in Fig. 5, but for turbulent nitrate flux divergence. Contours indicate potential density. Yellow and cyan markers denote euphotic layer depths estimated from photosynthetically active radiation and the method of Lee et al. (2007), respectively (color figure online) 


\subsection{Flux divergence at greater depths}

Divergence of the vertical fluxes was clearly observed at mid-depths in the region of the KOTA and the KE along the $155^{\circ} \mathrm{E}$ section (Sts. 14-16), and at depths from the surface to the subsurface in the ESM (Fig. 13). Along the $155^{\circ}$ E section, intense divergence/convergence $\left[O\left(10^{-8}\right) \mathrm{mmol}\right.$ $\mathrm{m}^{-3} \mathrm{~s}^{-1}$ ] was identified in the upper part of the North Pacific Intermediate Water (26.0-26.8 $\sigma_{\theta}$, Fig. 13a). Prominent divergence/convergence around the North Pacific Intermediate Water density was also observed at $600 \mathrm{dbar}$ beneath St. 19 (subtropical gyre), and at 400 dbar beneath St. 1 (KOTA), where enhancement of fluxes associated with the elevation of diffusivity was evident. In the ESM, divergence/convergence peaks of $O\left(10^{-7}\right) \mathrm{mmol} \mathrm{m}^{-3} \mathrm{~s}^{-1}$ were observed at depths down to $300 \mathrm{dbar}$ (Fig. 13c). The density at these depths almost reached $27.0 \sigma_{\theta}$, suggesting that more direct transport of nitrate from these depths to the surface occurred in the ESM.

\section{Discussion}

In this study, we used direct measurements to estimate nitrate fluxes in the western North Pacific. The observed magnitudes vary considerably, and a flux at the base of the euphotic zone of $O\left(10^{-6}\right) \mathrm{mmol} \mathrm{m}^{-2} \mathrm{~s}^{-1}$ was identified in the ESM due to active internal tides (Fig. 10f). In other parts of the subarctic gyre, fluxes of $1-8 \times 10^{-7} \mathrm{mmol} \mathrm{m}^{-2} \mathrm{~s}^{-1}$ were observed at the base of the euphotic zone (Fig. 10d, e). In contrast, the magnitude of the fluxes at the base of the euphotic zone in the subtropical gyre was estimated to be smaller than $1 \times 10^{-7} \mathrm{mmol} \mathrm{m}^{-2} \mathrm{~s}^{-1}$ (Fig. 10d). In the frontal areas, including the KE and the KOTA, the fluxes at the base of the euphotic zone were $O\left(10^{-7}\right.$ to $\left.10^{-6}\right) \mathrm{mmol}$ $\mathrm{m}^{-2} \mathrm{~s}^{-1}$ (Fig. 10d, e).

In the eastern North Pacific, Hayward (1987) estimated the turbulent nitrate flux in the subsurface as $0.4-1.6 \times 10^{-7} \mathrm{mmol} \mathrm{m}^{-2} \mathrm{~s}^{-1}$ in the subtropical region by multiplying diffusivity and nitrate distributions obtained from non-simultaneous observations. Fernández-Castro et al. (2015) estimated nitrate diffusive fluxes due to salt fingers plus mechanical turbulence in the eastern part of the North Pacific Tropical Gyre as $1.8 \pm 2.2 \times 10^{-6} \mathrm{mmol} \mathrm{m}^{-2} \mathrm{~s}^{-1}$. The level of fluxes at the base of the euphotic zone observed here in the subtropical gyre is the same as that reported by Hayward (1987) but smaller than that estimated by Fernández-Castro et al. (2015). The difference in the fluxes between those of the present study and those from Fernández-Castro et al. (2015) is caused by both the difference of the vertical gradient of nitrate $(0.011 \pm 0.037$ and $0.142 \pm 0.084 \mathrm{mmol} \mathrm{m}^{-4}$, respectively) and that of the vertical diffusivity $\left(0.14 \pm 0.13 \times 10^{-5}\right.$ and $1.8 \pm 2.8 \times 10^{-5}$ $\mathrm{m}^{2} \mathrm{~s}^{-1}$, respectively). Note that the values for the present study are from Sts. 16 to 22; for vertical diffusivity, we used the center value of the bootstrap method at each station for comparison with the previous study, and the $95 \%$ confidence interval of the stations ranged from 0.046 to $0.59 \times 10^{-5}$ $\mathrm{m}^{2} \mathrm{~s}^{-1}$. In contrast to the observations of Fernández-Castro et al. (2015) conducted in March, our observations were made from August to September. Thus, the development of a deeper nitracline and calm weather conditions in summer might produce the weaker gradient of nitrate and lower diffusivity near the surface observed in the present study. The level of turbulent nitrate flux in the subtropical gyre in the present study, $O\left(10^{-8}\right) \mathrm{mmol} \mathrm{m}^{-2} \mathrm{~s}^{-1}$, is one order smaller than that of nitrate fixation (another dominant source of nitrate in oligotrophic regions) reported by Shiozaki et al. (2009) $\left(2.94-17.6 \times 10^{-7} \mathrm{mmol} \mathrm{m} \mathrm{m}^{-2} \mathrm{~s}^{-1}\right)$ in the subtropical oligotrophic North Pacific along $155^{\circ}$ E $\left(16^{\circ}-28^{\circ} \mathrm{N}\right)$, although their observations were made in winter. FernándezCastro et al. (2015) reported that nitrate diffusion dominates nitrate fixation in the eastern part of the North Pacific using concurrent observations; thus, further studies, especially those in the same season, are required to draw firm conclusions. The magnitude of $O\left(10^{-7}\right.$ to $\left.10^{-6}\right) \mathrm{mmol} \mathrm{m}^{-2} \mathrm{~s}^{-1}$ that was estimated in the frontal areas including the KE and the KOTA is of the same order as that of new production in the
Fig. 14 Vertical distribution of turbulent nitrate flux divergence at a Sts. $14-16$ and $\mathbf{b}$ the Emperor Sea Mounts (ESM), with respect to density. The gray line denotes the statistical mean of each $0.5 \mathrm{~kg} \mathrm{~m}^{-3}$. KOTA means the Kuroshio-Oyashio Transition Area and KE means the Kuroshio Extension, respectively
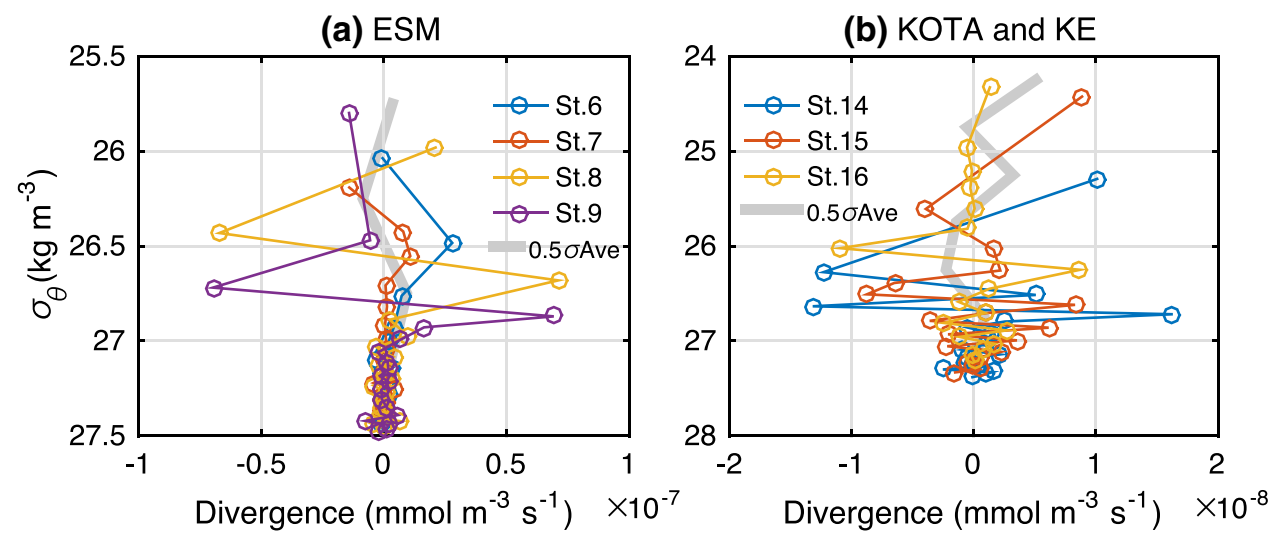
$\mathrm{KE}$ in August $\left[O\left(10^{-6}\right) \mathrm{mmol} \mathrm{m} \mathrm{m}^{-2} \mathrm{~s}^{-1}\right]$ estimated from data provided by Yokouchi et al. (2006), assuming the Redfield ratio of $\mathrm{C}: \mathrm{N}=106: 16$ (where $\mathrm{C}$ is carbon and $\mathrm{N}$ is nitrogen).

At greater depths (higher densities), relatively large flux divergence/ convergences were observed in the ESM (Fig. 13c). We, therefore, calculated a statistical mean of the divergence in each $0.5 \sigma_{\theta}$ range in the region (Fig. 14a). Then, divergence in 26.5-27.0 $\sigma_{\theta}$ and convergence in 25.5-26.5 $\sigma_{\theta}$ were estimated. As the isosurface of $25.5 \sigma_{\theta}$ was located almost at the surface in the ESM (Fig. 3), the convergence in 25.5-26.5 $\sigma_{\theta}$ may contribute to nutrient transport from the density of North Pacific Intermediate Water to the surface. In addition, substantial flux divergence was estimated in the KOTA and KE (Fig. 13a), with flux divergence (convergence) in the density range 26.5-27.0 $\sigma_{\theta}$ $\left(25.5-26.5 \sigma_{\theta}\right)$ (Fig. 14b). Thus, we also calculated a statistical mean of the divergence for Sts. 14-16 (Fig. 14b). Although the mean showed divergence in 26.5-27.0 $\sigma_{\theta}$ that corresponds to the core density of North Pacific Intermediate Water, the mean in 25.5-26.5 $\sigma_{\theta}$ was evaluated as convergence $\left[O\left(10^{-9}\right) \mathrm{mmol} \mathrm{m}^{-3} \mathrm{~s}^{-1}\right]$. Convergence due to turbulent diffusivity can be regarded as nutrient transport from the core of North Pacific Intermediate Water to lighter density in the subtropical gyre. In addition, if the convergence reaches up to the core density of subtropical mode water, it may play an important role in nutrient transport from the North Pacific Intermediate Water to the lower latitude surface (Sarmiento et al. 2004) because subtropical mode water is connected to the surface through wintertime mixing. A more detailed evaluation of the nutrient transport from the North Pacific Intermediate Water to subtropical mode water is required. The flux observed at the upper boundary of the subtropical mode water, $O\left(10^{-7}\right)$ mmol m $\mathrm{m}^{-2} \mathrm{~s}^{-1}$ (Fig. 9a, St. 18), is far smaller than that indirectly estimated from profiling float data by Sukigara et al. (2011), $9 \times 10^{-6} \mathrm{mmol} \mathrm{m}^{-2} \mathrm{~s}^{-1}$. Because the vertical gradient of nitrate is similar $\left(\sim 0.05 \mathrm{mmol} \mathrm{m}^{-4}\right)$ in the present study and that of Sukigara et al. (2011), the difference in diffusivity between them is responsible for the difference in the fluxes. As the measurement of turbulence at the stations was conducted only once, the seasonal- and monthly-scale variabilities of turbulence, including heavy weather conditions, may explain the difference. In addition, shorter timescale variation caused by the internal tides can also affect the estimation. Since there was only a single deployment at each station, we might have missed enhancements of turbulence due to short-term internal tides that occur on timescales of a few hours. Other possible reasons for the difference include the fact that the observations were made in different seasons (from August to September in this study and May to July in Sukigara et al. 2011) and that Sukigara et al. (2011) assumed a one-dimensional balance of oxygen for estimating diffusivity.
To discuss the energy source of the observed dissipation, the vertically averaged dissipation rate throughout the water column, $\langle\varepsilon\rangle_{\mathrm{WC}}$ was estimated at each station. We employed $E_{\text {wind }}$ with zero lag and the nearest grid data from the deployment after confirmation of the lag-correlation analysis (Supplemental Fig. 1). Latitudinal distributions of $\langle\varepsilon\rangle_{\mathrm{WC}}, E_{\text {wind }}$, and $D_{\text {tide }}$ along each transect are shown in Fig. 15. In addition to those in the ESM, elevations of $D_{\text {tide }}$ $\left(>10^{-3} \mathrm{~W} \mathrm{~m}^{-2}\right)$ were also estimated in the lower latitudes of the subtropical gyre $\left(<30^{\circ} \mathrm{N}\right)$, where characteristic topography existed (Fig. 2). In the subtropical gyre region $<30^{\circ}$ $\mathrm{N},\langle\varepsilon\rangle_{\mathrm{WC}}$ was also elevated $\left(>2 \times 10^{-10} \mathrm{~W} \mathrm{~kg}^{-1}\right)$. In contrast, along $160^{\circ} \mathrm{E}$, although $D_{\text {tide }}$ was small $\left(<0.4 \times 10^{-4} \mathrm{~W} \mathrm{~m}^{-2}\right)$, $\langle\varepsilon\rangle_{\mathrm{WC}}$ had relatively high values, implying a wind influence, especially at $40^{\circ} \mathrm{N}$ and $44^{\circ} \mathrm{N}$. At $47^{\circ} \mathrm{N}$ near the subarctic front, although there was a wider range of uncertainty in the turbulence, the elevation of $\langle\varepsilon\rangle_{\mathrm{WC}}$ was suggested, whereas $E_{\text {wind }}$ and $D_{\text {tide }}$ were small. Thus, near-inertial waves may be responsible. In another frontal region, at St. $15,\langle\varepsilon\rangle_{\mathrm{WC}}$ was elevated $\left(>4 \times 10^{-10} \mathrm{~W} \mathrm{~kg}^{-1}\right)$ in spite of weak $E_{\text {wind }}$ and $D_{\text {tide }}$, suggesting turbulence enhancement due to the near-inertial waves near the KE as mentioned by Kaneko et al. (2012) and/or Nagai et al. (2015). Weather conditions were calm before the turbulence measurement at St. 15, with neither developed cyclones nor typhoons (e.g., mean wind intensity for 20 days and its standard deviation at $10 \mathrm{~m}$ estimated from the J-OFURO3 data was $6.4 \pm 2.1 \mathrm{~m} \mathrm{~s}^{-1}$ ), implying frontal processes as a possible source of the turbulence (Alford et al. 2013; Nagai et al. 2015) in addition to the near-inertial waves propagating from higher latitudes (e.g., Garrett 2001; Alford 2003). These near-inertial waves caused by the frontal processes may lead to the large discrepancy between dissipation and $E_{\text {wind }}$. In total, there was a significant positive correlation between $\langle\varepsilon\rangle_{\mathrm{WC}}$ and $D_{\text {tide }}$, and between $\langle\varepsilon\rangle_{\mathrm{WC}}$ and $E_{\mathrm{wind}}(r=0.43, p<0.05$, and $r=0.55$, $p<0.01$, respectively, not shown). We divided the data into three groups according to the magnitude of $D_{\text {tide, }}$; the upper third as the high- $D_{\text {tide }}$ group (Sts. 6, 8, 9, 19, 20, 21, and 22), the next third as the moderate- $D_{\text {tide }}$ group (Sts. 7, 10, 12, 16, 17,18 , and T1), and the lower third as the low- $D_{\text {tide }}$ group (Sts. 1, 3, 5, 11,13,14, and 15). Then, an analysis of covariance was conducted with $E_{\text {wind }}$ as the covariate and $\langle\varepsilon\rangle_{\mathrm{WC}}$ as the dependent variable. Although the slopes of the regression lines were not significantly different $[F(2,15)=0.58$, $p=0.57]$, there was a significant effect of $D_{\text {tide }}$ on levels of $\langle\varepsilon\rangle_{\mathrm{WC}}$ after taking account of the effect of $E_{\text {wind }}$ [Fig. 16, $F(2,17)=5.71, p<0.05]$. Therefore, although dissipation in the whole water column would be affected by the surface wind, the difference due to the level of tidal mixing was also significant.

This study has shown how the enhancement of fluxes due to internal tides in the ESM compares with other subarctic regions. The ESM region is expected to contain hotspots of 

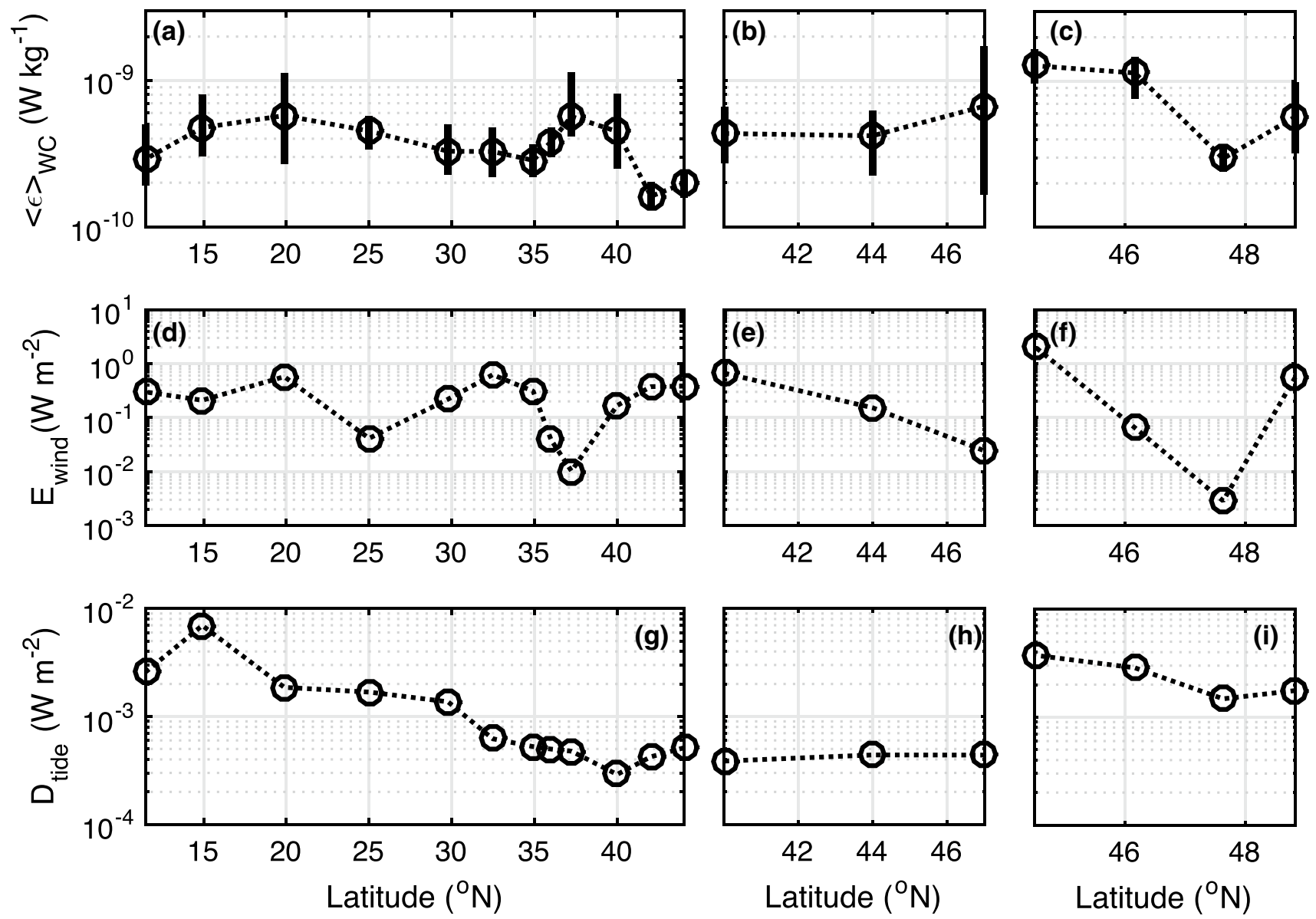

Fig. 15 Latitudinal distributions of $\mathbf{a}-\mathbf{c}$ vertically averaged dissipation rate, $\mathbf{d}-\mathbf{f} E_{\text {wind }}$, and $\mathbf{g}-\mathbf{h} D_{\text {tide }}$ (see Sect. 2.3). Error bars indicate $95 \%$ confidence intervals

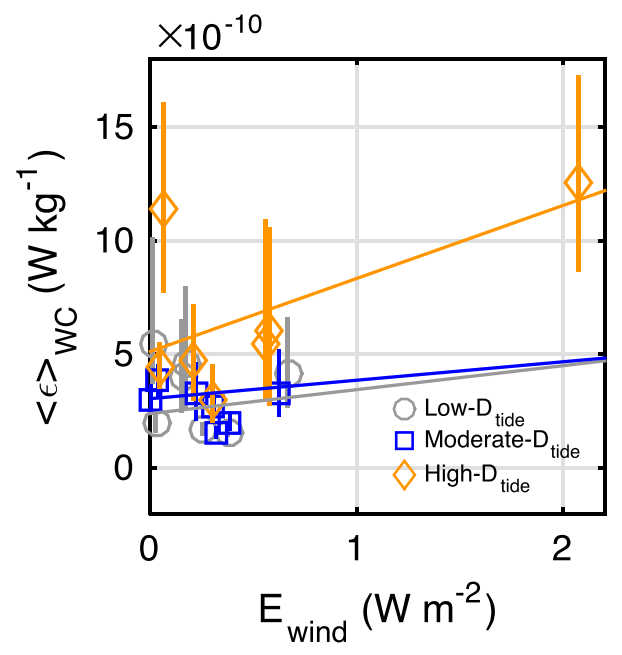

Fig. 16 Scatter plot of vertically averaged dissipation rate against $E_{\text {wind. }}$. Error bars indicate $95 \%$ confidence intervals. Solid and dashed lines denote the linear regression and confidence interval of the slope with respect to each group, respectively vertical redistribution of heat and materials, including nutrients. In the subtropical gyre, where there is thought to be a weak nitracline and elevated diffusivity due to internal tides, fluxes at the subsurface can be strengthened if the vertical gradient of nitrate is increased locally. Such an increase in the gradient can be temporarily caused by cyclonic eddies such as at St. 17 (Figs. 1b, 3d). Thus, frontal areas in the subtropical gyre, such as the subtropical counter currents where active eddy activity was reported (e.g., Qiu and Chen 2011), might be expected to act as a nutrient transport path in the subtropical gyre, in addition to the KE. The KE and KOTA have been shown to be key regions of nutrient transport from North Pacific Intermediate Water into less dense waters. However, it should be noted that the present study is based on one-time sparse measurements of turbulence that are unlikely to be sufficient to capture the patchy turbulence caused by the short-term internal waves, and the active variability around fronts and eddies in these regions. Therefore, future work will require long-term repeat observations of vertical diffusivity, including mooring measurements and profiling floats equipped with turbulence sensors to clarify 
nitrate circulation. As the first step, the basin-scale variability in the vertical nitrate flux provided by the present study will help improve our understanding of nitrate sources for biological productivity in the western North Pacific.

Acknowledgements We thank the captain, officers, and crew of the R/V Hakuho-Maru. We thank all onboard scientists, especially $\mathrm{Mr}$. H. Nagae, for their help in deploying the VMP. We also express our gratitude to Prof. H. Ogawa for providing data for $1 \%$ light depth, and Dr. T. Ikeya for his analysis of the nitrate data obtained by ISUS. We also thank Dr. C. Sukigara for providing nitrate bottle data. We also thank two anonimous reviewers for their variable comments and suggestions. This study was supported by a Grant-in-Aid for Scientific Research (S) (\#20221002) and Scientific Research on Priority Areas (\#18067002) from the Japan Society for the Promotion of Science (JSPS), and by a JSPS Fellowship (\#090J09478). The preparation of this manuscript by HK and SI was supported by KAKENHI (Grantin-Aid for Scientific Research on Innovative Areas) Grant numbers JP15H05823 (OMIX project) and JP18H03956. The scientific data used to make figures of this paper are available at https://ocg.aori.utokyo.ac.jp/omix/Kaneko_etal_2020JO/.

Open Access This article is licensed under a Creative Commons Attribution 4.0 International License, which permits use, sharing, adaptation, distribution and reproduction in any medium or format, as long as you give appropriate credit to the original author(s) and the source, provide a link to the Creative Commons licence, and indicate if changes were made. The images or other third party material in this article are included in the article's Creative Commons licence, unless indicated otherwise in a credit line to the material. If material is not included in the article's Creative Commons licence and your intended use is not permitted by statutory regulation or exceeds the permitted use, you will need to obtain permission directly from the copyright holder. To view a copy of this licence, visit http://creativecommons.org/licenses/by/4.0/.

\section{References}

Alford MH (2003) Redistribution of energy available for ocean mixing by long-range propagation of internal waves. Nature 423(159162):2003. https://doi.org/10.1038/nature01628

Alford MH, Shcherbina AY, Gregg MC (2013) Observations of nearinertial gravity waves radiating from a frontal jet. J Phys Oceanogr 43:1225-1239. https://doi.org/10.1175/JPO-D-12-0146.1

Cannon GA (1966) Tropical waters in the western Pacific Oceans, August-September 1957. Deep-Sea Res 13:1139-1148. https:// doi.org/10.1016/0011-7471(66)90705-4

Carr ME, Lewis MR, Kelley D, Jones B (1995) A physical estimate of new production in the equatorial Pacific along $150^{\circ} \mathrm{W}$. Limnol Oceanogr 40(1):138-147. https://doi.org/10.4319/ 10.1995.40.1.0138

Chisholm SW (1992) Phytoplankton size in primary productivity and biogeochemical cycles in the sea. Plenum, New York, pp 213-237

D’Asaro E, Lee C, Rainville L, Thomas L, Harcourt R (2011) Enhanced turbulence and energy dissipation at ocean fronts. Science 332(6027):318-322. https://doi.org/10.1126/science.1201515

de Lavergne C, Falahat S, Madec G, Roquet F, Nycander J, Vic C (2019) Toward global maps of internal tide energy sinks. Ocean Model 137:52-75. https://doi.org/10.1016/j.ocemod.2019.03.010

Eppley RW, Renger EH, Harrison WG (1979) Nitrate and phytoplankton production in southern California coastal waters. Limnol Oceanogr 24(3):483-494. https://doi.org/10.4319/ 10.1979.24.3.0483
Favorite F, Dodimead AJ, Nasu K (1976) Oceanography of the Subarctic Pacific region, 1960-71. Bull Int North Pac Comm 33:1-187

Fernández-Castro B, Mouriño-Carballido B, Benítez-Barrios VM, Chouciño P, Fraile-Nuez E, Graña R, Piedeleu M, RodríguezSantana A (2014) Microstructure turbulence and diffusivity parameterization in the tropical and subtropical Atlantic, Pacific and Indian Oceans during the Malaspina 2010 expedition. DeepSea Res I 94:15-30. https://doi.org/10.1016/j.dsr.2014.08.006

Fernández-Castro B, Mouriño-Carballido B, Marañón E et al (2015) Importance of salt fingering for new nitrogen supply in the oligotrophic ocean. Nat Commun 6:8002. https://doi.org/10.1038/ ncomms 9002

Garrett C (2001) What is the "near-inertial" band and why is it different from the rest of the internal wave spectrum? J Phys Oceanogr 31:962-971. https://doi.org/10.1175/1520-0485(2001)031\%3c096 2:WITNIB\%3e2.0.CO;2(2001)

Gregg MC (1987) Diapycnal mixing in the thermocline-a review. J Greophys Res 92(C5):5249-5286. https://doi.org/10.1029/JC092 iC05p05249

Hayward TL (1987) The nutrient distribution and primary production in the Central North Pacific. Deep-Sea Res Part A 34:1593-1627. https://doi.org/10.1016/0198-0149(87)90111-7

Horii S, Takahashi K, Shiozaki T, Hashihama F, Furuya K (2018) Stable isotopic evidence for the differential contribution of diazotrophs to the epipelagic grazing food chain in the midPacific Ocean. Glob Ecol Biogeogr 27:1467-1480. https://doi. org/10.1111/geb.12823

Itoh S, Kaneko H, Kouketsu S, Okunishi T, Tsustumi E, Ogawa H, Yasuda I (2020) Vertical eddy diffusivity in the subsurface pycnocline across the Pacific. J Oceanogr. https://doi.org/10.1007/ s10872-020-00589-9

Johnson K, Coletti L (2002) In situ ultraviolet spectrophotometry for high resolution and long-term monitoring of nitrate, bromide and bisulfide in the ocean. Deep-Sea Res I 49(7):1291-1305. https://doi.org/10.1016/S0967-0637(02)00020-1

Kaneko H, Yasuda I, Komatsu K, Itoh S (2012) Observations of the structure of turbulent mixing across the Kuroshio. Geophys Res Lett 39:L15602. https://doi.org/10.1029/2012GL052419

Kaneko H, Yasuda I, Komatsu K, Itoh S (2013) Observations of vertical turbulent nitrate flux across the Kuroshio. Geophys Res Lett 40(12):3123-3127. https://doi.org/10.1002/grl.50613

Kawai H (1969) Statistical estimation of isotherms indicative of the Kuroshio axis. Deep-Sea Res Suppl 16:109-115

Ledwell J, Watson A, Law C (1993) Evidence for slow mixing across the pycnocline from an open-ocean tracer-release experiment. Nature 364:701-703. https://doi.org/10.1038/364701a0

Lee Z, Weidemann A, Kindle J, Arnone R, Carder KL, Davis C (2007) Euphotic zone depth: its derivation and implication to ocean-color remote sensing. J Geophys Res 112:C03009. https ://doi.org/10.1029/2006JC003802

Lewis MR, Harrison WG, Oakey NS, Hebert D, Platt T (1986) Vertical nitrate fluxes in the oligotrophic ocean. Science 234:870873. https://doi.org/10.1126/science.234.4778.870

Masuzawa J (1969) Subtropical mode water. Deep-Sea Res 16(5):463-472. https://doi.org/10.1016/0011-7471(69)90034-5

Mori K, Uehara K, Kameda T, Kakehi S (2008) Direct measurements of dissipation rate of turbulent kinetic energy of North Pacific subtropical mode water. Geophys Res Lett 35:L05601. https:// doi.org/10.1029/2007GL032867

Moum JN, Osborn TR (1986) Mixing in the main thermocline. J Phys Oceanogr 16:1250-1259. https://doi.org/10.1175/15200485(1986)016\%3c1250:MITMT\%3e2.0.CO;2

Mouriño-Carballido B, Graña R, Fernàndez A, Bode A, Varela M, Domínguez JF, Escànez J, Armas DD, Marañón E (2011) Importance of N2 fixation vs. nitrate eddy diffusion along a 
latitudinal transect in the Atlantic Ocean. Limnol Oceanogr 56(3):999-1007. https://doi.org/10.4319/1o.2011.56.3.0999

Nagai T, Tandon A, Kunze E, Mahadevan A (2015) Spontaneous generation of near-inertial waves by the Kuroshio Front. J Phys Oceanogr 45(9):2381-2406. https://doi.org/10.1175/ JPO-D-14-0086.1

Nagai T, Durán GS, Otero DA, Mori Y, Yoshie N, Ohgi K et al (2019) How the Kuroshio Current delivers nutrients to sunlit layers on the continental shelves with aid of near-inertial waves and turbulence. Geophys Res Lett 46:6726-6735. https://doi.org/10.1029/2019G L082680

Nagasawa M, Hibiya T, Yokota K, Tanaka Y, Takagi S (2007) Microstructure measurements in the mid-depth waters of the North Pacific. Geophys Res Lett 34:L05608. https://doi. org/10.1029/2006GL028695

National Geophysical Data Center (2006) 2-minute Gridded Global Relief Data (ETOPO2) v2. National Geophysical Data Center, NOAA. doi:https://doi.org/10.7289/V5J1012Q. https://ngdc.noaa. gov/mgg/global/etopo2.html. Accessed 8 Apr 2020

Niwa Y, Hibiya T (2001) Numerical study of the spatial distribution of the M-2 internal tide in the Pacific Ocean. J Geophys Res Oceans 106(C10):22441-22449. https://doi.org/10.1029/2000jc000770

Oakey NS, Elliott JA (1982) Dissipation within the surface mixed layer. J Phys Oceanogr 13(2):171-185. https://doi.org/10.1175/15200485(1982)012\%3c0171:DWTSML\%3e2.0.CO;2

Osborn TR (1980) Estimates of the local-rate of vertical diffusion from dissipation measurements. J Phys Oceanogr 10:83-89. https://doi.org/10.1175/1520-0485(1980)010\%3c0083:EOTLR $\mathrm{O} \% 3 \mathrm{e} 2.0 . \mathrm{CO} ; 2$

Qiu B, Chen SM (2011) Interannual variability of the North Pacific Subtropical Countercurrent and its associated mesoscale eddy field. J Phys Oceanogr 40(1):213-225. https://doi. org/10.1175/2009jpo4285.1

Re3data.Org (2016) AVISO+. re3data.org-registry of research data repositories. https://doi.org/10.17616/R3B332. Accessed 1 Apr 2020

Sarmiento JL, Gruber N, Brzezinski MA, Dunne JP (2004) High-latitude controls of thermocline nutrients and low latitude biological productivity. Nature 427:56-60. https://doi.org/10.1038/natur $\mathrm{e} 02127$

Shiozaki T, Furuya K, Kodama T, Takeda S (2009) Contribution of N-2 fixation to new production in the western North Pacific Ocean along $155^{\circ}$ E. Mar Ecol Prog Ser 377:19-32. https://doi. org/10.3354/meps07837
Sukigara C, Suga T, Saino T, Toyama K, Yanagimoto D, Hanawa K, Shikama N (2011) Biogeochemical evidence of large diapycnal diffusivity associated with the subtropical mode water of the North Pacific. J Oceanogr 67(1):77-85. https://doi.org/10.1007/ s10872-011-0008-5

Tanaka T, Hasegawa D, Yasuda I, Tsuji H, Fujio S, Goto Y, Nishioka J (2019) Enhanced vertical turbulent nitrate flux in the Kuroshio across the Izu Ridge. J Oceanogr 75:195-203. https://doi. org/10.1007/s10872-018-0500-2

Thorpe SA (2004) Recent developments in the study of ocean turbulence. Annu Rev Earth Planet Sci 20:91-109. https://doi. org/10.1146/annurev.earth.32.071603.152635

Tomita H, Hihara T, Kako S, Kubota M, Kutsuwada K (2018) An introduction to J-OFURO3, a third-generation Japanese ocean flux data set using remote-sensing observations. J Oceanogr 75:171-194. https://doi.org/10.1007/s10872-018-0493-x

Waterhouse AF, MacKinnon JA, Nash JD, Alford MH, Kunze E, Simmons HL, Polzin KL, St. Laurent LC, Sun OM, Pinkel R, Talley LD, Whalen CB, Huussen TN, Carter GS, Fer I, Waterman S, Naveira Garabato AC, Sanford TB, Lee CM (2014) Global patterns of diapycnal mixing from measurements of the turbulent dissipation rate. J Phys Oceanogr 44(7):1854-1872. https://doi. org/10.1175/JPO-D-13-0104.1

Welschmeyer NA (1994) Fluorometric analysis of chlorophyll- $a$ in the presence of chlorophyll- $b$ and phaeopigments. Limnol Oceanogr 39:1985-1992. https://doi.org/10.4319/lo.1994.39.8.1985

Whalen CB, MacKinnon JA, Talley LD (2018) Large-scale impacts of the mesoscale environment on mixing from wind-driven internal waves. Nat Geosci 11:842-847. https://doi.org/10.1038/s4156 1-018-0213-6

Yasuda I (1997) The origin of the North Pacific intermediate water. J Geophys Res 102:893-909. https://doi.org/10.1029/96JC02938

Yasuda I (2003) Hydrographic structure and variability in the Kuroshio-Oyashio transition area. J Oceanogr 59:389-402. https://doi. org/10.1023/A:1025580313836

Yokouchi K, Tsuda A, Kuwata A, Kasai H, Ichikawa T, Hirota Y, Adachi K, Asanuma I, Ishida H (2006) Simulated in situ measurements of primary production in Japanese waters. In: Kawahata $\mathrm{H}$, Awaya YA (eds) Global climate change and response of carbon cycle in the equatorial Pacific and Indian Oceans and adjacent landmasses. Elsevier Science, Amsterdam, pp 65-88 